UNIVERSIDADE DE SÃO PAULO

FACULDADE DE ECONOMIA, ADMINISTRAÇÃO E CONTABILIDADE DE RIBEIRÃO PRETO

DEPARTAMENTO DE ECONOMIA PROGRAMA DE PÓS-GRADUAÇÃO EM ECONOMIA - ÁREA:

ECONOMIA APLICADA

\title{
O sistema de bonificação de São Paulo: uma análise do alcance e impacto do programa em seus cinco primeiros anos
}

RIBEIRÃO PRETO 

Prof. Dr. Marco Antonio Zago

Reitor da Universidade de São Paulo

Prof. Dr. Dante Pinheiro Martinelli

Diretor da Faculdade de Economia, Administração e Contabilidade de Ribeirão Preto

Prof. Dr. Renato Leite Marcondes

Chefe do Departamento de Economia

Prof. Dr. Sérgio Naruhiko Sakurai

Coordenador do Programa de Pós-graduação em Economia 


\author{
UNIVERSIDADE DE SÃO PAULO \\ FACULDADE DE ECONOMIA, ADMINISTRAÇÃO E CONTABILIDADE DE \\ RIBEIRÃO PRETO \\ DEPARTAMENTO DE ECONOMIA \\ PROGRAMA DE PÓS-GRADUAÇÃO EM ECONOMIA - ÁREA: \\ ECONOMIA APLICADA
}

\title{
O sistema de bonificação de São Paulo: uma análise do alcance e impacto do programa em seus cinco primeiros anos
}

\begin{abstract}
Dissertação apresentada ao Programa de Pós-Graduação em Economia - Área: Economia Aplicada da Faculdade de Economia, Administração e Contabilidade de Ribeirão Preto da Universidade de São Paulo, para obtenção do título de Mestre em Ciências. Versão Corrigida. A original encontra-se disponível na FEA-RP/USP.
\end{abstract}

Laiz Barbosa de Carvalho

Orientador: Prof. Dr. Elaine Toldo Pazello

RIBEIRÃO PRETO

2017 
Autorizo a reprodução e divulgação total ou parcial deste trabalho, por qualquer meio convencional ou eletrônico, para fins de estudo e pesquisa, desde que citada a fonte.

Carvalho, Laiz Barbosa de

O sistema de bonificação de São Paulo: uma análise do alcance e impacto do programa em seus cinco primeiros anos/ Laiz Barbosa de Carvalho; Orientador: Prof. Dr. Elaine Toldo Pazello

RIBEIRÃO PRETO, 2017- 57 p. : il.

Dissertação (Mestrado) - Universidade de São Paulo, 2017.

1. Educação. 2. Programa de bônus. 3. Desempenho das escolas. I. Orientador: Prof. Dr. Elaine Toldo Pazello. II. Universidade de São Paulo - USP - Ribeirão Preto. III. Faculdade de Economia, Administração e Contabilidade. IV. O sistema de bonificação de São Paulo: uma análise do alcance e impacto do programa em seus cinco primeiros anos 


\section{Agradecimentos}

Os agradecimentos principais são direcionados à Elaine Toldo Pazelo, Luiz Guilherme Dácar da Silva Scorzafave e Reynaldo Fernandes pelos inúmeros conselhos e ideias dados ao longo desse mestrado e, principalmente, pela paciência que demonstraram em seus ensinamentos.

Não poderia deixar de agradecer a todos aqueles que me acompanharam, quase que diariamente, durante essa jornada: a turma de Mestrado de 2015. Por todos os estudos, estresses, discussões, desesperos e parcerias, muito obrigada! Um agradecimento especial à Sabrina que fez com que a saudade de São Paulo fosse menor sentida quando compartilhada.

Agradeço também a todos os professores da FEA-RP pelos ensinamentos e por nos estimularem a seguir em frente. Em especial, agradeço a minha orientadora, Elaine, que permitiu a existência deste trabalho e que conseguiu me mostrar a beleza da docência.

À minha família pelo infinito apoio quando decidi continuar a estudar. Obrigada por estarem presentes nos momentos de insegurança, dúvida e muito estudo. Mãe, pai e Mayara, uma parte dessa conquista é de vocês.

E por último, mas não menos importante, Vinicius. Obrigada por colocar a pulga atrás da minha orelha em 2013 quando disse "Por que não o mestrado?". Obrigada por estar comigo nos momentos pré e pós ANPEC, na indecisão de continuar em frente ou desistir. Obrigada por me acompanhar e incentivar, de longe e de perto, no ínicio e fim do mestrado, me ajudando a sempre encontrar a motivação pra continuar. Obrigada por me mostrar o longo prazo, por me mostrar que a dedicação vale a pena, e, porque não, pelas broncas dadas nos momentos certos, que me fizeram colocar o pé no chão e a mente para trabalhar. Sem você esse título não seria meu. Muito Obrigada! 


\section{Resumo}

CARVAlHO, L. B. O sistema de bonificação de São Paulo: uma análise do alcance e impacto do programa em seus cinco primeiros anos. 2017. Dissertação (Mestrado) - Faculdade de Economia, Administração e Contabilidade de Ribeirão Preto, Universidade de São Paulo, Ribeirão Preto, 2017.

Nos últimos anos diversos países, desenvolvidos ou subdesenvolvidos, adotaram algum tipo de programa de incentivos à professores, seja este financeiro (aumentos de salários permanentes ou temporários) ou no sentido de melhorar o ambiente de trabalho do professor. Seguindo esse exemplo, estados brasileiros adotaram o incentivo financeiro como tentativa de melhorar o desempenho dos alunos. Neste trabalho será analisado o programa de bonificação a professores do Estado de São Paulo implementado em dezembro de 2008, direcionado a professores e funcionários de escolas que atingem as metas pré-estabelecidas para cada ano. O objetivo do estudo é analisar o padrão de recebimento do bônus entre as escolas durante os cinco primeiros anos de vigência do programa (2009 a 2013) e verificar se o incentivo financeiro consegue produzir mudanças na rotina escolar a fim de melhorar o desempenho da escola como um todo. Em função do desenho do programa, para algumas escolas, a probabilidade de alcance da meta, em um determinado momento, é bastante alta, não requerendo dessas escolas um esforço de fato substantivo. Para outras, no entanto, o alcance da meta é de fato algo mais distante que requer mudança de comportamento. Assim, a ideia é comparar o desempenho das escolas paulistas no ambiente em que a política de bonificação exista e em um ambiente no qual esta não exista (ambiente contrafactual construído nesse trabalho) a fim de identificar o acréscimo ou decréscimo de esforço e desempenho que pode ser creditado ao incentivo gerado pela política. Através dessa análise pode-se mensurar quanto do desempenho efetivo das escolas advém de suas características socioeconômicas (e particularidades) e quanto é resultado da exposição à nova política. Com a análise realizada neste trabalho é possível concluir que a política gera pouco incentivo para que escolas com desempenho baixo ou intermediário atinjam as metas pré-definidas pela Secretaria de Estado de São Paulo. O que ocorre nos cinco anos analisados) é que escolas com alto desempenho e que realizam pouco ou nenhum esforço dada a política recebem o bônus na maioria dos anos.

Palavras-chave: Educação, Programa de Bônus, Desempenho escolar 


\begin{abstract}
CARVALHO, L.B. São Paulo's bonus system: an analysis of the scope and impact of the program in its first five years 2017. Dissertation (Masters) Faculdade de Economia, Administração e Contabilidade de Ribeirão Preto, Universidade de São Paulo, Ribeirão Preto, 2017.

Teachers incentive programs is a recurring theme in the literature, whether these incentives are financial (permanent salary increases or temporary) or to improve the teacher's work environment. Several Brazilian states have adopted the financial incentive as an attempt to improve performance and students' knowledge. This article will review the São Paulo program implemented in December 2008, for teachers and school staff that reach pre-set targets for each year. The objective of the study is to analyze the bonus receiving pattern between schools during the first five years of the program (2009-2013) and verify if the financial incentive can produce changes in the school routine (such as changes in teaching practices and increased participation of parents in the education of their children) in order to improve the school's performance as a whole. Depending on the program design, for some schools, the probability of achieving the goal, at any given time, is quite high, not requiring a great effort from these schools. For others, however, the achievement of the goal is almost impossible, what requires a change of behavior. Thus, the idea is to compare school performances in two different environments: one where the bonus policy exists and another that it does not (created in this work). This comparison will allow the identification of how much effort each school put through the exams and which part of these effort is related to the socioeconomics characteristics that these schools are inserted on and which is from the actual exposure to the policy. With this analisis is possible to conclude that the program generates lower incentives to schools with medium and lower performances. Schools with higher performance always get the bonification without doing any or small effort.
\end{abstract}

Keywords: Education, bonification programs, school results. 
Sumário

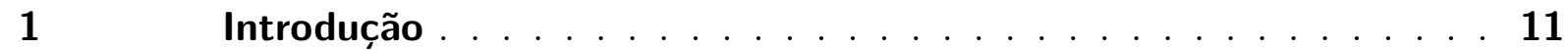

2 Revisão Bibliográfica . . . . . . . . . . . . . . . . . . 14

$3 \quad 0$ programa de bonificação de São Paulo . . . . . . . . . . . . . . . 20

$4 \quad$ Metodologia . . . . . . . . . . . . . . . . . . . 25

$4.1 \quad$ Alcance da Política . . . . . . . . . . . . . . . . . . . 25

4.2 Esforço e Desempenho das Escolas Estaduais Paulistas . . . . . . . . . . 27

$4.3 \quad$ Dados . . . . . . . . . . . . . . . . . . . 34

$4.3 .1 \quad$ Construção dos Dados . . . . . . . . . . . . . . . . . . 34

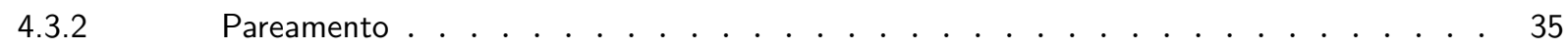

$4.4 \quad$ Análise da distribuição do bônus . . . . . . . . . . . . . . . . 39

$5 \quad$ Resultados . . . . . . . . . . . . . . . . . . 41

5.1 Construção do Ambiente Contrafactual . . . . . . . . . . . . . . . . . . . 41

5.2 Análise de Esfoço . . . . . . . . . . . . . . . . . 44

$6 \quad$ Análise de Robustez . . . . . . . . . . . . . . . . . . 47

$7 \quad$ Considerações Finais . . . . . . . . . . . . . . . . . . . 50

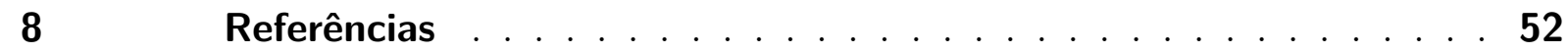

$\begin{array}{ll}\text { ANEXOS } & 55\end{array}$

ANEXO A - PARÂMETROS UTILIZADOS PARA A CRIAÇÃO DO CONTRAFACTUAL . . . . . . . . . . . 57 


\section{Lista de ilustrações}

Figura 1 - Variáveis explicativas utilizadas no pareamento - Escolas Estaduais Paulistas $-5^{\circ}$ ano . . . . . . . . . . . . . . 36

Figura 2 - Variáveis explicativas utilizadas no pareamento - Escolas do Sul do país $-5^{\circ}$ ano . . . . . . . . . . . . . . . . . 37

Figura 3 - Variáveis explicativas utilizadas no pareamento - Escolas Estaduais Paulistas $-9^{\circ}$ ano . . . . . . . . . . . . . . . . . . . 37

Figura 4 - Variáveis explicativas utilizadas no pareamento - Escolas do Sul do país - $9^{\circ}$ ano . . . . . . . . . . . . . . . . . . . 38

Figura 5 - Dispersão de Notas nos ambientes contrafactual e efetivo - $5^{\circ}$ ano . . . 43

Figura 6 - Dispersão de Notas nos ambientes contrafactual e efetivo - $9^{\circ}$ ano . . . 43 


\section{Lista de tabelas}

Tabela 1 - Valores de referência do SARESP para os exames de Língua Portuguesa 21

Tabela 2 - Valores de referência do SARESP para os exames de Matemática . . . 22

Tabela 3 - Exemplo Idesp e Metas de escolas estaduais do Estado de São Paulo em 2012 e $2013 \ldots \ldots$. . . . . . . . . . . . . . . . . . 26

Tabela 4 - Características das escolas do $5^{\circ}$ ano de acordo com o recebimento do bônus entre 2009 e 2013 . . . . . . . . . . . . . . . . . 39

Tabela 5 - Características das escolas do $9^{\circ}$ ano de acordo com o recebimento do bônus entre 2009 e 2013 . . . . . . . . . . . . . . . . . . . . . 40

Tabela 6 - Análise de Esforço observado para as escolas do $5^{\circ}$ ano utilizando o diferencial entre o desemepnho efetivo e contrafactual . . . . . . . . . . 44

Tabela 7 - Análise de Esforço observado para as escolas do $9^{\circ}$ ano utilizando o diferencial entre o desemepnho efetivo e contrafactual . . . . . . . . . . 45

Tabela 8 - Percepção de esforço e recebimento do bônus para as escolas do $5^{\circ}$ ano 45

Tabela 9 - Percepção de esforço e recebimento do bônus para as escolas do $9^{\circ}$ ano 46

Tabela 10 - Desempenho Contrafactual $5^{\circ}$ ano - estatísticas descritivas . . . . . . . 48

Tabela 11 - Desempenho Contrafactual $9^{\circ}$ ano - estatísticas descritivas . . . . . . . 48

Tabela 12 - Porcentagem de escolas que receberam o bônus . . . . . . . . . . . . 49

Tabela 13 - Percepção de esforço e recebimento do bônus para análise de robustez $-5^{\circ}$ ano . . . . . . . . . . . . . . . . . . 49

Tabela 14 - Percepção de esforço e recebimento do bônus para análise de robustez - $9^{\circ}$ ano . . . . . . . . . . . . . . . . . . . 4 49

Tabela 15 - Parâmetros observados na estimação da equação (9) - 50 ano . . . . . . 57

Tabela 16 - Parâmetros observados na estimação da equação $(9)$ - $9^{\circ}$ ano . . . . . . 57 



\section{Introdução}

A partir de 2007 as políticas de bonicação surgiram em diversos estados do Brasil como forma de incentivar os professores a se esforçarem mais em sala de aula, através do cumprimento de metas pré-estabelecidas por cada governo. O primeiro estado a implementar esse tipo de política foi o Amazonas (dezembro de 2007) seguido de Minas Gerais, Pernambuco (ambos em julho de 2008), São Paulo e Roraima (dezembro de 2008). Não há um padrão quanto ao desenho dos sistemas de bonificação das diferentes redes de ensino no Brasil. Alguns são baseados no cumprimento de metas de proficiência escolar, mas também há casos em que a bonificação é baseada no desenvolvimento de projetos ou na realização de inovações no ensino. O sistema de bonicação torna-se realmente mais disseminado no Brasil a partir de 2011, com mais de dez estados brasileiros adotando algum tipo de bonicação aos funcionários. Esse tipo de programa também se espalhou entre as redes municipais, embora não haja um levantamento sistemático dos programas municipais e suas características. Este trabalho irá estudar em detalhes o programa de bonicação paulista que está entre os programas mais antigos (permitirá fazer uma análise de 5 anos) implantados no Brasil.

Em maio de 2008, o governo do Estado de São Paulo iniciou o Programa de Qualidade da Escola (PQE) a $\mathrm{m}$ de promover a melhoria da qualidade e da equidade do sistema de ensino. Já em dezembro de 2008, um sistema de bonicação aos professores e funcionários das escolas paulistas foi implantado, desde que fossem atingidas metas baseadas na assiduidade dos professores e no desempenho dos alunos no SARESP (Sistema de Avaliação do Rendimento Escolar do Estado de São Paulo).

As metas foram determinadas pelo governo do Estado de São Paulo com base no índice de desempenho, o IDESP (Índice de Desenvolvimento da Educação do Estado de São Paulo) que mede a qualidade das escolas através do desempenho dos alunos no SARESP e de sua taxa de progressão. Desde o início do programa até 2013, o IDESP médio da rede estadual paulista cresceu de $35,7 \%$ no $5^{\circ}$ ano do ensino fundamental e caiu 3,12\% no $9^{\circ}$ ano. Essa variação nos resultados gera diversos debates na literatura sobre a real ecácia do programa no desempenho dos alunos e se esse tipo de política é a melhor 
opção para aumentar a qualidade do ensino oferecido pelas escolas.

A lógica para que o programa obtenha êxito é que o incentivo nanceiro melhore o desempenho dos professores na sala de aula de forma que os alunos aprendam mais. Porém não há um consenso entre os estudos sobre o real impacto de incentivos nanceiros no desempenho acadêmico. Lavy (2004), Muralidharan e Sundararaman (2009) e Glewwe e Ilias (2003) encontraram efeitos positivos de programas de incentivos nanceiros sobre o desempenho em matemática e leitura de alunos de Israel, Índia e Quênia, respectivamente. Ao contário, Dee e Wyckoff (2015) não encontraram impacto signicativo sobre o desempenho dos alunos ao analisar o programa IMPACT do distrito de Columbia nos Estados Unidos.

Scorzafave, Oshiro e Dorigan (2015) e Tavares e Ponczek (2014) encontraram efeitos positivos da política de bônus do Estado de São Paulo no desempenho dos alunos do $5^{\circ}$ ano (porém esse efeito é passageiro) tanto em matemática quanto em português, mas esse efeito não se repete para os alunos do $9^{\circ}$ ano.

A política de bonicação de Pernambuco possui incentivos muito parecidos com a política de São Paulo, com critérios baseados na presença do professor e no desempenho dos alunos. Ferraz e Bruns (2012) concluíram que escolas com desempenho próximo a meta tem maior incentivo para melhorar seus resultados nos próximos anos do que aquelas que caram muito longe da meta.

Conversando com a literatura nacional sobre o tema, o objetivo deste trabalho é analisar o programa de bônus de São Paulo entre os anos de 2009 e 2013 (ou seja, nos cinco primeiros anos de sua existência). Foram escolhidos os cinco primeiros anos do programa para análise principalmente pela disponibilização dos dados (tanto do SARESP quanto da Prova Brasil). Mas também por esses anos englobarem certa estabilidade em relação às Notas Explicativas adotadas pela Secretaria de Educação do Estado de São Paulo, que mudaram em 2009 e 2014.

Serão analisados dois pontos especícos: o primeiro deles é a análise do padrão de recebimento do bônus entre as escolas estaduais paulistas, já que se pode observar 
comportamentos bastante heterogêneos: porque esse é o período no qual a metodologia para o pagamento do bônus é mais constante, já que ocorreram poucas mudanças nas Notas Técnicas no período (há grandes mudanças em 2009 e 2014).

Serão analisados dois pontos específicos: o primeiro dele é a análise do padrão de recebimento do bônus entre as escolas estaduais paulistas paulistas, já que se pode observar comportamentos bastante heterogêneos: algumas escolas nunca receberam o bônus, outras receberam no início da política e pararam de receber, algumas só receberam o benefício recentemente e há também escolas que foram contempladas em todos os anos da análise. Em outras palavras, o objetivo é investigar que tipo de características e/ou comportamento podem definir o recebimento ou não do bônus.

O segundo interesse deste é analisar o impacto da política no esforço despendido pelas escolas a fim de produzir um melhor desempenho nos exames padronizados. Com essa análise de esforço será possível verificar se esse esforço advém do incentivo criado pela própria política ou de outras características já existentes nas escolas.

O diferencial desse trabalho está na criação de um ambiente contrafactual no qual o desemepnho das escolas poderá ser medido sem a influência do programa de bonificação. Com isso será possível medir se as escolas realizaram algum esforço pela diferença de desempenho nos dois ambientes.

Para a criação desse ambiente contrafactual serão utilizadas escolas estaduais de outros estados brasileiros sem política de bonificação . A escolha dessas escolas será feita utilizando-se o método de Propensity Score Matching. Por meio do cálculo do IDESP dessas escolas (usando os dados da Prova Brasil) será simulado qual seria o IDESP das escolas paulistas nesse ambiente sem a política.

Além do desempenho das escolas foram consideradas variáveis socioeconômicas que identificam o cenário no qual a escola está inserida. A ideia é explorar se, por exemplo, o fato de a escola ter professores e diretores com altos salários e alunos com melhor background socioeconômico, faz com que a chance da mesma ser contemplada pelo bônus seja mais alta independente do incentivo oferecido pela política. O presente 
estudo contribui para a literatura na medida em que introduz a análise em um ambiente contrafactual construído para verificar se o cenário em que a escola se insere é, por si só, determinante para o recebimento do bônus.

Com a análise do ambiente contrafactual e das características das escolas será possível verificar se a política de bonificação gera algum dispendimento extra de esforço para um melhor desempenho das escolas ou se, dadas outras características, o desemepnho já é alto o suficiente fazendo com que o incentivo não gere grandes diferenças.

O restante do trabalho se divide da seguinte maneira: detalham-se os divergentes estudos da literatura no capítulo 2; a estruturação da política de bonificação paulista no capítulo 3; a metodologia e a base de dados são descritas no capítulo 4; no capítulo 5, apresentam-se os resultados encontrados. Por fim, no capítulo 6, têm-se as considerações finais.

\section{Revisão Bibliográfica}

Pesquisas mais recentes mostram que o papel do professor é de extrema importância para o aprendizado (HANUSHEK, 2005). Rockoff (2004) utilizou dados em painel de escolas de dois distritos de Nova Jersey entre os anos de 1998 e 2001 e concluiu que um aumento de um desvio padrão na qualidade do professor aumenta em aproximadamente 0,1 desvio padrão a performance de alunos em leitura e matemática em exames nacionais padronizados. A experiência do professor também aumenta o desempenho do aluno nas provas, especialmente em leitura: 0,17 desvio padrão em média a mais para professores com 10 ou mais anos de experiência.

Embora haja substancial consenso sobre a importância da qualidade do professor, ainda existe bastante discussão sobre como medir essa qualidade, bem como sobre mecanismos para incrementar tal qualidade como forma de melhorar a educação dos países. Hanushek et al (1999) e Lazear (2001) concordam que medir a qualidade de um professor seja extremamente difícil e que a melhora dos incentivos atrai professores mais 
bem qualicados e com maior disposição para ensinar. Segundo Lazear (2001), no entanto, apenas aumentar o salário não é uma solução, sendo as características demográcas (como localidade da escola, quantidade de alunos provenientes de famílias de baixa renda, entre outros) de grande relevância no desempenho de professores.

Entre os incentivos considerados para aumentar a qualidade dos professores estão as políticas de aumento salarial, tanto ao longo da carreira, como de 'salário temporário' (bônus); há também políticas voltadas para melhorar a assiduidade do professor, sua qualificação, dentre outras. Esta revisão foca nos trabalhos que analisam os impactos das políticas de bonificação, tendo em vista o objetivo do presente estudo. A literatura sobre o impacto das políticas de bonificação mostra tantos resultados positivos quanto negativos e, portanto, seus resultados são inconclusivos. Essa literatura também se caracteriza por analisar o impacto sobre os resultados educacionais dos alunos e, não, propriamente, sobre a qualidade dos professores.

Isso pode ser observado, principalmente, nos estudos americanos os quais medem a qualidade dos professores através do valor adicionado gerado pelos exames de proficiência realizado pelos alunos, ou seja, esse valor adicionado não se relaciona com as características dos professores, mas sim com o quanto as notas aumentaram ou decresceram com o passar dos anos.

Goodman e Turner (2012) analisaram o programa de bônus de Nova Iorque no qual, em 2007, selecionou aleatoriamente quase 200 escolas com alunos provenientes de famílias de baixa renda. Professores poderiam ganhar até $\$ 3.000$ dependendo do desempenho dos alunos. Em escolas com grupos pequenos de professores responsáveis pelo ensino, os alunos obtiveram melhores resultados, porém o efeito foi pequeno (0,08 desvio-padrão em matemática).

A análise de incentivos nem sempre encontra efeitos positivos dos programas implementados. Spinger et al (2012) analisa o impacto do pagamento por performance nas notas dos alunos e nas práticas estruturais através do experimento POINT para escolas da Nashville Public Schools (MNPS) entre 2006 e 2009 (34 escolas e 20000 estudantes). 
A medida de valor agregado do professor foi o crescimento da nota do aluno no TCAP comparado com o ano anterior. Não foram encontradas diferenças significativas entre alunos com professores do grupo de tratamento e controle.

O programa TAP criado em 1990 para melhorar a qualidade dos professores em mais de 200 escolas em 13 estados foi implantado em Chicago em 2007 com adaptações (inclui bônus para diretores e outros funcionários além dos professores). Glazerman e Seifullah (2012) selecionaram aleatoriamente 16 escolas para o grupo de tratamento e 16 para o de controle. Após a aplicação dos métodos de Propensity Score Matching e diferenças em diferenças encontrou-se que a diferença entre ter ou não participado do TAP é muito baixa. Os resultados são nulos para leitura e um aumento de 0,05 desvio padrão para matemática.

Fryer (2011) analisou o programa implementado por Nova Iorque que distribuiu \$75M para 20.000 professores. Em média, a escola receberia $\$ 180.000$ se atingisse a meta completa e $\$ 90.000$ se atingisse entre $75 \%$ e $100 \%$ da meta. O programa de bonificação não gerou melhora no desempenho dos alunos. Na verdade, o desempenho dos mesmos diminuiu no período analisado (-0,015 desvio padrão em matemática e -0,011 desvio padrão em leitura para o ensino fundamental e -0,048 desvio padrão e -0,032 desvio padrão, respectivamente, para o ensino médio).

Analisando programas em outras localidades que não os Estados Unidos, Martins (2009) analisou o programa nacional de bonificação por performance de alunos em Portugal entre os anos de 2002 e 2008. Para utilizar o método de diferenças em diferenças, as escolas foram separadas em dois grupos: tratamento (escolas públicas de Portugal) e controle (escolas públicas de Madeira e Azores).

Concluiu-se que o pagamento individual por performance diminui o desempenho dos alunos, principalmente em exames nacionais (cerca de -0,4 desvio padrão). Ao utilizar o método de diferenças triplas, verificou-se um aumento na inflação das notas dos alunos. Ao se analisar as especificações e as variáveis dependentes, percebeu-se que não há diferenças entre os grupos de tratamento e controle. 
Quando se compara programas de incentivos aplicados a escolas particulares e públicas observa-se maior sucesso nas primeiras que nas últimas. Isso se deve, principalmente, pela sindicalização dos professores que lecionam em escolas públicas. Kingdon e Teal (2003) analisaram as habilidades dos alunos, background dos pais e os recursos disponíveis em escolas particulares e públicas da Índia. O estudo encontrou relação positiva entre o pagamento por performance e a melhora de desempenho dos alunos, porém essa relação é maior (e significativa estatisticamente) para escolas particulares.

Além do desempenho dos alunos nas provas, foram realizados questionários que captaram informações dos alunos, professores e condições das escolas. Concluiu-se que professores sindicalizados recebem menos (em sua maioria, professores de escolas públicas) que professores em escolas privadas. Nessas últimas, há relação positiva entre o pagamento por performance do professor e o desempenho do aluno.

Ballou (2001) retirou dados de quatro grandes questionários nacionais de professores e administradores escolares nos Estados Unidos. Para tentar isolar efeitos que não sejam o mérito, a amostra foi controlada por: 1) salário oferecido para professores iniciantes com graduação; 2) salário oferecido para novos professores com pós-graduação; 3) diferença entre 2) e o salário de instrutor com a mesma formação, mas com 20 anos de experiência. Concluiu-se que escolas particulares fazem melhor uso do pagamento por mérito do que escolas públicas. Nas escolas particulares, o pagamento por mérito é uma forma de atrair melhores professores (mais qualificados) e mantê-los. Já nas escolas públicas, o pagamento por mérito é um jogo de soma zero, com fundos vindos de reservas que poderiam ser usados para aumentar salários.

Nessas localidades, percebe-se que os sindicatos de professores têm desempenhado um papel fundamental na obstrução da disseminação de planos de incentivo de remuneração no setor público. Nos distritos onde os professores não têm representação sindical, a incidência do pagamento por mérito é quase tão grande quanto em escolas particulares.

Um estudo mais recente sobre incentivos (Dee e Wycko (2015)) analisa o controverso programa IMPACT do distrito de Columbia (EUA), que separa os professores em grupos de baixa e alta performance ameaçando os primeiros com demissão e beneciando 
os últimos com compensação nanceira. Concluiu-se que a ameaça de demissão aumenta as discussões entre os professores de baixa performance, mas aumenta seus desempenhos na sala de aula. Ademais, encontraram que incentivos nanceiros aumentam a performance dos professores melhor qualicados.

Fryer (2012) realizou um experimento para alinhar incentivos de pais, professores e alunos em 50 escolas com baixa performance em Houston entre os anos de 2010 e 2011. Alunos recebiam $\$ 2$ por objetivo de matemática realizado, pais também recebiam $\$ 2$ por objetivo realizado de seus filhos e $\$ 20$ por comparecimento em reunião entre pais e professores para discutir o desempenho da criança. Professores recebiam $\$ 6$ por reunião com pais e até $\$ 10.100$ em bônus pelo desempenho de seus alunos em exames padronizados.

Alunos nas escolas tratadas realizaram $125 \%$ mais objetivos em matemática que alunos em escolas do grupo de controle. Em média, pais que participaram do programa compareceram cerca de 2 vezes mais à reunião de pais. Houve um aumento de 0.081 desvio padrão no desempenho dos alunos em matemática que participaram do programa.

Resultados mais duradouros são encontrados quando a política de incentivo nanceiro é de longo prazo, ou seja, quando o aumento do salário vale até o m da carreira, podendo ser utilizado para cálculo da aposentadoria. Atkinson et al (2009) chegaram a estas conclusões com estudos na Inglaterra, em que os professores que alcançavam padrões aceitáveis em determinadas áreas (conhecimento e entendimento do ensino, coordenação do aprendizado, efetividade prossional, características prossionais e desempenho dos alunos) receberiam 2000 libras a mais no salário (bônus permanente). Os resultados mostraram um aumento da nota dos alunos que tiveram aula com os professores que participaram do programa, mostrando alguma evidência de que o programa afetou o esforço dos professores.

No caso dos estudos brasileiros, a grande maioria analisa o impacto de políticas públicas de bonificação para as escolas estaduais e municipais. Estudos nos quais algumas escolas recebem uma mudança direta e pontual, normalmente advindas da iniciativa privada, (como os casos do Quênia e Índia) não são cmuns no país.Além disso, dentre os programas de bonificação existentes hoje, nenhum deles gera recebimento de gratificação 
permanente aos funcionários (aumento permanente para a composição do salário para a aposentadoria). Isso faz com que grande parte dos sindicatos aceite a bonificação, mas clute por revisão e aumentos salariais permanentes.

Ferraz e Bruns (2012) analisaram o programa de bonicação do estado de Pernambuco nos anos de 2009 a 2011 e concluíram que escolas com metas mais ambiciosas alcançam melhores resultados, bem como as escolas com professores melhor instruídos e com mais experiência. Escolas que não receberam o bônus em 2009, mas obtiveram desempenho próximo ao da meta, melhoram mais do que as escolas que dicilmente atingiram o bônus em 2009 (cando longe da meta).

Tavares e Ponczek (2014) e Scorzafave, Oshiro e Dorigan (2015) estudaram os efeitos de políticas de bônus do governo do Estado de São Paulo sobre a performance dos alunos.

Tavares e Ponczek (2014) analisaram o programa de bonicação juntamente com a lei do quinquênio que aumenta o salário do funcionário em $5 \%$ a cada 5 anos de exercício do trabalho. O objetivo do estudo é vericar o impacto da variação do salário do professor no desempenho dos alunos, ou seja, se turmas com professores que recebem maiores salários têm melhor desempenho. Turmas cujos professores recebem salários mais baixos respondem positivamente ao aumento de salário. Foram utilizadas as notas do SARESP de 2007 e 2009 para alunos do $5^{\circ}$ e $9^{\circ}$ anos do ensino fundamental e $3^{\circ}$ ano do ensino médio. Um aumento salarial de $1 \%$ por ano gera um aumento de desempenho de cerca de 0,04 desvio-padrão nas notas de Língua Portuguesa e Matemática para alunos do $9^{\circ}$ ano. Para o $3^{\circ}$ ano do ensino médio, este aumento é de 0,05 desvio-padrão. Scorzafave, Oshiro e Dorigan (2015) analisam o programa de bonicação de São Paulo utilizando a Prova Brasil de 2007, 2009 e 2011

e os métodos de pareamento por escore de propensão e diferenças em diferenças para medir o impacto na prociência dos alunos (de $5^{\circ}$ e $9^{\circ}$ anos do ensino fundamental). Entre os anos de 2007 e 2009, vericou-se efeitos positivos para Matemática (0,42 desvio padrão) e Português (0,14 desvio padrão) para o $5^{\circ}$ ano. Os efeitos para o $9^{\circ}$ ano foram negativos. 
Aproximando-se de um dos objetivos desse trabalho, Bresolin (2014) tem um olhar diferente sobre esse tipo de programa. Analisa dados de diferentes tipos de sistemas de bonicação estaduais (São Paulo, Ceará, Pernambuco, Minas Gerais, Amazonas, Goiás, Espírito Santo e Rio de Janeiro) para vericar se a oferta de bônus promove realmente um desempenho diferenciado do diretor e do professor a ponto de modicar indicadores intermediários que possam proporcionar uma melhora na aprendizagem dos alunos. Entre os indicadores intermediários estão as práticas pedagógicas dos professores, absenteísmo e rotatividade de professores e interlocução com familiares para garantir a frequência dos alunos. Os dados utilizados foram os questionários da Prova Brasil e dividiu-se os programas pelo ano de implementação, tipo e série. Os resultados obtidos através de pareamento pelo escore de propensão e diferenças em diferenças foram mistos, ocorrendo em geral impactos positivos na melhora das práticas pedagógicas dos professores (correção da lição de casa) para o $5^{\circ}$ ano, mas sem mudanças visíveis no $9^{\circ}$ ano. Algo que se torna evidente é que os programas baseados no desempenho dos alunos e na assiduidade do professor (como o de São Paulo) têm efeitos signicativos nos elementos intermediários comparados aos programas sem essas contrapartidas.

Como a melhora da qualidade da educação é tema fundamental e recorrente em países em desenvolvimento como o Brasil, tentar compreender os determinantes de uma boa educação é essencial para que se possa atingi-la. Dessa forma, estudos que contribuam para uma melhor compreensão dos problemas educacionais e como melhorá-los são de grande importância para que o país atinja um nível desejável de educação. Como colocado, esse trabalho procura contribuir com essa literatura ao analisar o programa de bonificação do estado de São Paulo. A próxima seção descreve tal programa.

\section{O programa de bonificação de São Paulo}

As regras do programa de bonicação de São Paulo foram lançadas pelo Programa de Qualidade da Escola (PQE) em maio de 2008 e o projeto de lei em dezembro do mesmo ano propondo metas para aprimorar a qualidade de ensino oferecido no Estado 
de São Paulo. As metas pré-estabelecidas pela Secretaria de Educação do Estado de São Paulo para cada série de cada escola são baseadas no IDESP, indicador que mede a qualidade das escolas paulistas desde 2007. É composto por dois critérios: o desempenho dos alunos no exame de prociência SARESP e o uxo escolar em um determinado ano. O SARESP é realizado anualmente para alunos do $2^{\circ}$ (a partir de 2012 ), $3^{\circ}, 5^{\circ}, 7^{\circ}$ e $9^{\circ}$ do ensino fundamental e $3^{\circ}$ ano do ensino médio com questões de língua portuguesa, matemática e ciências da natureza. Além da prova, os alunos, professores, coordenadores e diretores devem preencher um questionário com perguntas especícas para cada esfera da comunidade escolar.

O IDESP é calculado pela multiplicação do índice de desempenho (ID) com o indicador de uxo (IF):

$$
I d e s p_{s}=I D_{s} \cdot I F_{s}
$$

Em que $I D_{s}$ é o indicador de desempenho para a série s e $I F_{s}$ é o indicador de fluxo para a série s.

O indicador de desempenho é medido pelos resultados em português e matemática do SARESP dos alunos do $5^{\circ}$ e $9^{\circ}$ anos do ensino fundamental e $3^{\circ}$ ano do ensino médio. Com as notas obtidas pelos alunos é possível dividi-los em quatro níveis de desempenho: abaixo do básico, básico, adequado e avançado. Os valores de referência para a denição do nível de desempenho de cada aluno são dados pelas tabelas a seguir:

Tabela 1: Valores de referência do SARESP para os exames de Língua Portuguesa

\begin{tabular}{rccc}
\hline \multicolumn{4}{c}{ Língua Portuguesa } \\
\hline Nível & $5^{\circ}$ ano EF & $9^{\circ}$ ano EF & $3^{\circ}$ ano EM \\
Abaixo do básico & $<150$ & $<200$ & $<250$ \\
Básico & 150 a $<200$ & 200 a $<275$ & $250 \mathrm{a}<300$ \\
Adequado & 200 a $<250$ & 275 a $<325$ & $300 \mathrm{a}<375$ \\
Avançado & $>250$ & $>325$ & $>375$ \\
\hline
\end{tabular}

Fonte: Nota Técnica IDESP 2009 - Secretaria do Estato de São Paulo

A distribuição de alunos pelo nível de desempenho representa a defasagem da 
Tabela 2: Valores de referência do SARESP para os exames de Matemática

\begin{tabular}{rccc}
\hline \multicolumn{4}{c}{ Matemática } \\
\hline Nível & $5^{\circ}$ ano EF & $9^{\circ}$ ano EF & $3^{\circ}$ ano EM \\
Abaixo do básico & $<175$ & $<225$ & $<275$ \\
Básico & $175 \mathrm{a}<225$ & $225 \mathrm{a}<300$ & $275 \mathrm{a}<350$ \\
Adequado & $225 \mathrm{a}<275$ & $300 \mathrm{a}<350$ & $350 \mathrm{a}<400$ \\
Avançado & $>275$ & $>350$ & $>400$ \\
\hline
\end{tabular}

Fonte: Nota Técnica IDESP 2009 - Secretaria do Estato de São Paulo

escola (def) em relação às expectativas de aprendizagem a partir da seguinte função:

$$
d e f_{j s}=\frac{\left(3 x A B_{j s}\right)+\left(2 x B_{j s}\right)+\left(1 x A d_{j s}\right)+\left(0 x A v_{j s}\right)}{100}
$$

Em que para cada série s e cada matéria j $A B_{j s}$ é o número de alunos avaliados no nível abaixo do básico em relação ao total de alunos avaliados, $B_{j s}$ refere-se à proporção de alunos avaliados no nível básico, $A d_{j s}$ a proporção de alunos no nível adequado e $A v_{j s}$ a proporção dos alunos no nível avançado.

A defasagem da escola é crescente com o grau de atraso escolar dos alunos em relação a proficiência e varia entre zero (quando todos os alunos estão no nível Avançado) e três (quando todos os alunos estão no nível Abaixo do Básico).

ID mostra o índice de desempenho das escolas, sendo crescente e variando em uma escala de zero a dez dependendo do bom desempenho da escola. O ID é calculado da seguinte forma:

$$
I D_{j s}=\left(1-\frac{d e f_{j s}}{3}\right) x 10
$$

Para o cálculo do IDESP, o índice de desempenho de cada escola será a média simples do ID de Matemática e ID de Língua Portuguesa:

$$
I D_{s}=\frac{I D_{L P}+I D_{M A T}}{2}
$$

O fluxo escolar é medido pela taxa de aprovação em cada etapa escolar coletada pelo Censo Escolar:

$$
I F_{s}=\frac{A_{i}}{T_{i}}
$$

Em que $A_{i}$ é o número de alunos aprovados e $T_{i}$ é o número de alunos matriculados. 
A metodologia da apuração do cumprimento das metas pré-estabelecidas sofreu alterações com o passar dos anos devido a ajustes necessários que foram implementados para uma análise de resultados mais apurada de cada escola, levando em conta além do desempenho dos alunos, o ambiente no qual a escola está inserida.

O Índice de Cumprimento (IC) em um determinado ano t para cada escola j é determinado pela seguinte equação:

$$
I C=\frac{I \operatorname{des} p_{j, t}-I \operatorname{Ies} p_{j, t-1}}{\operatorname{Meta}_{j, t}-I \operatorname{Ides} p_{j, t-1}}
$$

O Índice de Cumprimento varia entre 0\% e 120\%. Para valores superiores a 120\%, considera-se o cumprimento de $120 \%$ da meta, para valores negativos, considera-se o piso (zero).

Até 2008 as escolas apenas recebiam a bonificação se atingissem a partir de $100 \%$ da meta. A partir de 2009, com a atualização da Nota Técnica, valores intermediários também passaram a ser válidos, ou seja, qualquer avanço no IDESP de um ano para outro passa a ser bonificado.

Além disso, um adicional por qualidade passou a ser considerado (Índice de Qualidade) para o pagamento de bônus. Este índice posiciona a escola j em relação à média das outras escolas do estado e à meta de longo prazo de 2030:

$$
I Q=\frac{I d e s p_{j, t}-I \text { desp } p_{\text {agregado }}}{I \text { desp } p_{\text {meta } 2030}-\text { Idesp }_{\text {agregado }}}
$$

Em que o Idesp $p_{\text {agregado }}$ é a média dos resultados das escolas no período t e Idesp $p_{\text {meta2030 }}$ é a meta nal do IDESP a ser alcançada em 2030, comum para todas as escolas. Essa meta de longo prazo é de 7 para o $5^{\circ}$ ano, 6 para o $9^{\circ}$ ano e 5 para o $3^{\circ}$ ano do Ensino Médio.

Se a escola estiver acima da média da rede estadual (IDESP agregado) o adicional por qualidade (IQ) será positivo. Se a escola estiver abaixo da média da rede, IQ assume valor zero.

O valor pago como bônus é determinado pela soma dos Índices de Qualidade e Cumprimento, limitado entre 0\% e 120\%. Funcionários das escolas que possuem presença em 2/3 dos dias letivos terão direito ao recebimento do bônus. Para as escolas que 
cumprirem $100 \%$ da meta, o valor recebido será de 2,4 salários. Para as escolas que ultrapassarem os 100\%, a bonicação pode chegar a 2,9 salários. O número de salários recebidos é proporcional a porcentagem atingida da meta.

O benefício é pago sempre no nal do mês de março do ano seguinte ao apurado. No ano de 2013 o governo do Estado de São Paulo distribuiu 700 milhões de reais para 255 mil funcionários estaduais. Esses valores cresceram com o passar dos anos já que no início da política, março de 2009, o governo pagou 590 milhões para quase 196 mil funcionários.

A partir de 2014, o valor pago pelo bônus passou a ser determinado de maneira distinta (alteração do Índice de Cumprimento da Meta). Ao invés de ser determinado pela soma entre IC e IQ (limitado a 120\%), passou a ser determinado pela seguinte equação:

$$
I C M=[M A X(I C ; I Q)] x[1+(N S E x M O D)]
$$

Em que IC é o Índice de Cumprimento, IQ o Índice de Qualidade (ambos calculados com a mesma metodologia apresentada anteriormente), INSE é o Índice de Nível Socioeconômico de cada unidade escolar e MOD o modulador, valor percentual a ser aplicado como multiplicador do valor NSE.

Assim, o ICM passa a ser calculado pelo valor máximo entre IQ e IC, o Índice de Nível Socioeconômico e o Modulador. Esses dois últimos foram adicionados com o intuito de mensurar a heterogeneidade das escolas no sentido de atingir resultados de aprendizagem. São utilizados para a construção desse índice indicadores de renda, ocupação e escolaridade construídos com as respostas de questionários contextuais respondido pelos pais dos alunos em cada ano.

Os resultados obtidos foram convertidos em uma escala com variação entre zero e dez com um peso (fator modulador) aplicado a esse índice para calibrar o avanço da escola em relação aoI DES $P_{\text {meta2030. }}$

Como os dados utilizados nesse trabalho serão baseados nos desempenhos das escolas entre os anos de 2008 e 2013, foram utilizadas as Notas Técnicas vigentes para cada período na apuração do bônus a ser pago para as escolas. Ou seja, em 2008 utilizouse apenas o Índice de Cumprimento (IC) e entre os anos de 2009 e 2013, a soma entre o 
Índice de Cumprimento e o Índice de Qualidade $(I C+I Q)$.

\section{Metodologia}

Neste trabalho analisa-se o alcance da política de bônus das escolas paulistas nos primeiros anos de seu funcionamento (2008 a 2013) e o esforço realizado pelas escolas durante esse mesmo período. O conceito de esforço utilizado neste trabalho será a diferença de desempenho das escolas observada em dois ambientes: ambiente contrafactual (construído nesse tranbalho) e o real (desempenho efetivo das escolas). Se o desempenho real das escolas for maior do que o contrafactual, a conclusão será que o incentivo gerado pela política faz com que as escolas realizem maior esforço a fim de melhorar seus desempenhos em geral.

Para este estudo foi utilizada a metodologia de Propensity Score Matching para estabelecer as escolas mais parecidas com as escolas paulistas levando em consideração o vetor de características analisados; a definição do IDESP para as escolas fora do estado de São Paulo permitindo a comparação no desempenho de escolas expostas e não expostas a política de bonificação paulista; e por fim a estimação dos parâmetros que torna possível a projeção do desempenho das escolas paulistas em um ambiente sem política e a comparação com o real desempenho a fim de analisar se houve realização de esforço por parte das escolas.

Para isso, são utilizados dados da Prova Brasil de 2005 a 2013, o desempenho efetivo das escolas paulistas durante os anos de 2009 e 2013 e as diferentes metodologias adotadas pela Secretaria de Educação do Estado de São Paulo durante o período analisado.

\subsection{Alcance da Política}

O comportamento do recebimento do bônus das escolas paulistas ao longo do tempo não segue um padrão bem definido. Para entender melhor o comportamento entre as escolas paulistas é necessário compreender o funcionamento do programa de bonificação 
e sua implementação em dezembro de 2008.

Um dos motivos para que o padrão de recebimento das escolas mude com os anos é a forma pela qual as metas são estabelecidas. Estas mudam a cada ano conforme o desempenho da escola no ano anterior. Se a escola obteve desempenho muito superior à meta, esta será reajustada conforme o último resultado obtido pela escola. O mesmo ocorre se a escola ficou muito abaixo da meta.

Na tabela 3 pode-se observar um exemplo baseado em casos de escolas reais de como as metas2 funcionam e de que forma o índice de cumprimento é calculado.

Tabela 3: Exemplo Idesp e Metas de escolas estaduais do Estado de São Paulo em 2012 e 2013

\begin{tabular}{rccccc}
\hline \multicolumn{5}{c}{ Escola A } \\
\hline & Idesp 2011 & Idesp 2012 & Meta 2012 & Índice de Cumprimento & Meta 2013 \\
$5^{\circ}$ na EF & 4,32 & 4,99 & 4,47 & $120 \%$ & 5,09 \\
$9^{\circ}$ ano EF & 2,06 & 2,19 & 2,26 & $65 \%$ & 2,33 \\
$3^{\circ}$ ano EM & 2,11 & 1,80 & 2,31 & $0 \%$ & 1,91 \\
\hline
\end{tabular}

Fonte: Notas técnicas Secretaria do Estado de São Paulo 2012 e 2013

A Escola A parte de um IDESP 2011 de 4,32 para o $5^{\circ}$ ano do ensino fundamental, tendo uma meta de 4,47 para 2012. Ou seja, a meta da escola é avançar 0,15 no valor do IDESP do $5^{\circ}$ ano. No entanto, o valor efetivo obtido para essa série em 2012 foi de 4,99, o que representa um avanço de 0,67. Dessa forma, o avanço obtido pela escola foi maior do que o exigido pela meta resultando num cumprimento de meta de $447 \%$. Como o valor máximo a ser alcançado pela escola é $120 \%$, o Índice de Cumprimento do 5 o ano da Escola A assume esse valor, 120\%. Observando o desempenho da escola A para o $5^{\circ}$ ano em 2012 (IDESP 2012) o governo estipula a nova meta para o ano seguinte. Já que a escola obteve desempenho superior à meta do ano (IDESP 2012 de 4,99 contra a Meta 2012 de 4,47) sua meta para 2013 será baseada no desempenho do ano vigente (Meta 2013 de 5,09).

Analogamente, com relação ao $9^{\circ}$ ano do ensino fundamental e o $3^{\circ}$ ano do ensino médio os Índices de Cumprimento dessa escola serão de $65 \%$ e 0\%, respectivamente. Como a meta para o $9^{\circ}$ foi atingida parcialmente, a Meta 2013 será reajustada de acordo com 
o desempenho em 2012 (A nova meta será de 2,33 baseada no desempenho do IDESP 2012 que foi de 2,19). Já para o $3^{\circ}$ do Ensino Médio, cujo desempenho foi abaixo da meta estabelecida para 2012 (Meta 2012 de 2,31 e IDESP 2012 de 1,80), a Meta 2013 será menor que a Meta 2012 (1,91 contra 2,31, respectivamente), adequando-se a realidade da escola. Assim, as metas para o próximo ano se baseiam nos resultados obtidos no ano vigente representando as dificuldades ou facilidades de aprendizado observadas anteriormente dadas as características do próprio desenho da política.

\subsection{Esforço e Desempenho das Escolas Estaduais Paulistas}

Outro importante aspecto das políticas de bônus é seu impacto na quantidade de esforço realizado por alunos, professores e funcionários das escolas com consequente impacto no desempenho dos alunos. A política em função de seu desenho impõe, de maneira geral, níveis diferentes de esforço para cada escola já que essa precisa atingir metas pré-estabelecidas pela Secretaria de Educação a cada ano.

Além das metas serem constantemente ajustadas em função do desempenho da escola, o recebimento do bônus também está condicionado à posição da escola relativamente às demais escolas através do chamado Índice de Qualidade . Sendo assim, escolas com IDESP acima da média terão obviamente maiores chances de receber o bônus, independente do esforço que realizem. Além disso, uma escola que tenha recebido notas baixas em um ano por alguma razão que não uma redução de fato em sua qualidade, terá maiores chances de receber o bônus no ano seguinte em função de sua meta ser automaticamente reduzida. Por outro lado, há escolas que terão de fato de se esforçar para receber o bônus. Assim, pode-se concluir que a probabilidade de recebimento do bônus varia entre escolas e a hipótese deste trabalho é que essas diferenças de probabilidade levam a diferentes níveis de esforços entre as escolas expostas a mesma política.

Assim, iremos criar uma variável que capture o esforço que as escolas teriam que realizar a cada ano para serem contempladas pela política de bonificação. Essa variável de esforço corresponderá às relações existentes entre a meta estabelecida pela política para o desempenho da escola, o desempenho que seria observado em uma situação na qual a 
política não existisse e o desempeito efetivo das escolas.

O desafio desse trabalho está na construção da trajetória das notas das escolas paulistas em um ambiente sem política, ou seja,a projeção de qual seria o desempenho das escolas paulistas numa situação em que a política de bonificação não existe. Para se projetar tais desempenhos, trabalha-se com escolas de outras redes estaduais que não são expostas a nenhum tipo de política de bônus.

Inicialmente foi utilizado o método de Propensity Score Matching para encontrar o grupo de escolas mais parecido com as escolas estaduais paulistas utilizando o vetor de características das escolas, a estimação do modelo Probit (que indica a probabilidade de a escola ser ou não estadual) e o método do vizinho mais próximo e da condição de suporte comum.

A estimação do modelo de Propensity Score Matching foi realizado primeiramente com o grupo de escolas estaduais sem política de bonficação em todo o país com o objetivo de encontrar o grupo de escolas estaduais mais parecido com as escolas paulistas. Através dessa primeira estimação verificou-se que as escolas do Sul do país eram as que mais se encaixavam nesse grupo. O segundo passo foi encontrar, para cada escola estadual paulista, uma escola da região Sul que pudesse ser pareada.

Após o pareamento e a escolha de uma escola estadual do Sul do país para cada escola estadual paulista calculou-se o IDESP correspondente para essas mesmas escolas em cada ano observado. O IDESP foi calculado utilizando-se as Notas Técnicas divulgadas a cada ano pela Secretaria de Educação do Estado de São Paulo e a Prova Brasil como fonte de desempenho dos alunos de cada escola. A utilização da Prova Brasil foi possível a partir de 2007 porque tanto a última quanto o SARESP passaram a utilizar a mesma métrica, tornando possível a apuração de resultados do IDESP utilizando-se a Prova Brasil.

Isso permitiu verificar o desempenho das escolas em uma prova não impactada pela política (Prova Brasil) em um ambiente sem a exposição à mesma (redes estaduais do Sul do país).

A segunda etapa para a construção do ambiente contrafactual é a definição dos 
componentes de crescimento das notas a cada ano para que fosse possível não só definir o desempenho de cada escola antes da política, mas também durante os anos analisados.

Para isso, a equação (9) foi estimada a fim de definir qual o peso do desempenho anterior da escola e suas características econômicas têm na definição do desempenho futuro.

$$
\Delta Y_{i}=Y_{i t}-Y_{i t-1}=\alpha+\sum \beta_{i} X+\gamma Y_{i 0}+\epsilon
$$

Em que $Y t i$ indica o desempenho da escola no ano t, $Y_{i t-1}$ o desempenho da escola no ano t-1, $X_{i t}$ é o vetor de características da escola, $Y_{0}$ o desempenho da escola antes da existência da política (2007) e $\epsilon$ é o erro, com as hipóteses tradicionais das estimativas por MQO.

O desempenho da escola antes do início da política (2007) é utilizada como variável defasada no modelo, ou seja, a variável dependente é explicada por seus valores defasados e por suas características socieconômicas.

Para a composição do vetor Xit de características das escolas foram consideradas variáveis que não seriam influenciadas pela política, ou seja, variáveis que não mudam caso as escolas recebam o bônus durante os anos analisados. Para o vetor de características e de desemepnho das escolas foram utilizados os questionários e notas da Prova Brasil para os anos anteriores à política (2005 e 2007).

Assim, as seguintes variáveis foram retiradas dos questionários da Prova Brasil em todos os anos avaliados:

- Variável binária com valor igual a "1" se a escola possui biblioteca;

- Salário e proporção de professores e diretores das escolas com pós-graduação (especialização, mestrado ou doutorado);

- Proporção de alunos que moram com a mãe;

- Proporção de alunos que fizeram maternal;

- Proporção de mães de alunos com pelo menos o Ensino Médio Completo; e 
- Renda familiar média do aluno.

O fato da escola possuir ou não biblioteca faz parte das características estruturais da escola, característica esta que não deveria se alterar com o incentivo recebido pelos funcionários. zpar Como o incentivo financeiro não é permanente (não é utilizado para fins de cálculo de aposentadoria ou de progressão profissional) grandes alterações salariais advindas da política não são esperadas. A mesma coisa pode-se dizer da experiência anterior dos professores e da escolaridade, já que há poucos incentivos do governo estadual de São Paulo em especialização e pagamento de pós-graduação para professores da rede pública estadual.

Características socioeconômicas dos alunos das escolas não deveriam mudar com a exposição à política. O fato dos alunos frequentarem o maternal, de morarem com as mães, a escolaridade da mãe e a renda familiar não são características afetadas pela política. Com o acompanhamento dessas características durante os anos torna-se possível inferir o ambiente socioeconômico geral no qual as escolas estão inseridas.

Uma fragilidade da hipótese apresentada acima é o possível deslocamento de alunos "bons" para escolas com melhores desempenhos e maiores taxas de recebimento de bônus em busca de melhores condições de aprendizado. Isso faria com que o alto desempenho das escolas consideradas boas continuasse podendo aumentar em alguns casos; perpetuando as lacunas de aprendizado dentro do próprio Estado.

Para saber o quanto essa possível fragilidade afeta nossos resultados, comparamos as características das escolas que receberam o bônus 5 vezes e daquelas que nunca o receberam a fim de verificar de que forma as características dessas escolas evoluem ao longo do tempo

Dentre essas características estão a escolaridade das mães dos alunos, o fato dos mesmo frequentarem o maternal e a quantidade de reprovações observadas.

Entretanto, se uma migração de alunos e/ou professores realmente ocorre entre os anos de 2009 e 2013 a percepção de esforço gerada pela política de bonificação estará distorcida já que o melhor desempenho se dará, em grande parte, pelo fato de que alu- 
nos com melhores condições socioeconômica integram as escolas com melhores resultados; enquanto que as escolas inseridas em condições socioeconômicas piores continuariam atingindo baixos níveis de desempenho também pela saída desses alunos (apesar da migração entre escolas públicas depender de fatores burocráticos alheios apenas as vontades de pais, professores e alunos).

Então, para cada ano analisado, os parâmetros $\alpha, \beta$ e $\gamma$ advindos da estimação das escolas do Sul do país foram projetados para as escolas paulistas utilizando-se o vetor de características das escolas paulistas e seus desempenhos em 2007, para montar a diferença de desempenho a cada dois anos.

Assim, a partir dos coeficientes estimados na equação (9) é possível obter os parâmetros que definem o crescimento ou descrescimento do desempenho das escolas entre dois anos num ambiente sem política de bonificação. Isso tornou possível a criação de um ambiente contrafactual $Y_{t i *}$ para as escolas paulistas que indica a performance dessas mesmas escolas sem a política de bonificação.

Um empecilho na criação efetiva desse ambiente contrafactual para as escolas de São Paulo é o fato de a Prova Brasil ser realizada de dois em dois anos enquanto que o SARESP é anual. Para contornar esse problema foi realizada uma interpolação linear do IDESP para os anos faltantes no Stata. Essa interpolação não altera a média obserada de desempenho, mas pode afetar a trajetória.

Para a análise do esforço que as escolas teriam que realizar em função da política de bonificação serão analisadas as relações existentes entre o desempenho efetivo das escolas, o desempenho no ambiente contrafactual e o quão distante da meta pré-estabelecida esses desempenhos estão.

Uma limitação dessa comparação está na não divulgação pela Secretaria Estadual do Estado de São Paulo da metodologia para a definição das metas pré-estabelecidas a cada ano. Isso fez com que não fosse possível estimar as metas que estariam válidas no ambiente contrafactual. Assim, a análise do esforço irá comparar o quão distante os desempenhos efetivo e contrafactual estão da meta real para aquele ano e as relações entre 
essas variáveis.

A medida de esforço que a escola deve fazer para atingir a meta será representada pela diferença entre a meta a ser alcançada e o desempenho no ambiente contrafatual, ou seja, o incremento na nota que cada escola deve obter de seu desempenho sem incentivos (em um ambiente no qual a política não existe). Se essa diferença é positiva pode-se concluir que a escola deve fazer algum esforço para atingir a meta. Se essa diferença é negativa conclui-se que a escola, mesmo em um ambiente no qual não exista incentivos, já obtém resultados superiores a qualquer meta que poderia ser estabelecida. Além disso, o desempenho efetivo será incluído a fim de se verificar o quanto desse esforço requerido foi efetivamente realizado; ou seja, a diferença entre a meta pré-estabelecida pelo governo e o desempenho contrafactual é o esforço necessário que cada escola deve fazer a fim de receber o bônus. Já a diferença entre o desempenho efetivo e o contrafactual é o esforço efetivamente realizado.

- $Y_{t} \geq Y_{m}>Y_{t *}$ - Tanto o desempenho efetivo quanto a meta a ser alcançada são maiores que o desempenho no ambiente contracaftual. Pode-se inferir que as escolas nessa situação despendem maior esforço do que despenderiam sem o incentivo da política e essas escolas são bem-sucedidas na tarefa de bater a meta anual. Além disso, pode-se dizer que a meta ou é adequada ou é difícil de alcançar. As escolas que se encaixam nesse perfil serão as escolas do Grupo 1.

- $Y_{t} \geq Y_{t *} \geq Y_{m}-\mathrm{O}$ desempenho efetivo é maior do que o observado no ambiente contrafactual e esse último é maior do que a meta. Pode-se inferir que o desempenho obtido sem os incentivos da política já é maior do que a meta pré-estabelecida, fazendo com que a escola se esforce para conseguir o bônus, mesmo esse esforço não sendo tão grande, já que seu desempenho contrafactual já é maior que a meta. Neste caso pode-s inferir que a meta é fácil de ser alcançada. As escolas que se encaixam nesse perfil serão as escolas do Grupo 2.

- $Y_{m}>Y_{t *}>Y_{t}-$ Mesmo com o estímulo da política a nota efetiva é menor do que a observada no ambiente contrafactual que por sua vez também é menor do que 
a meta. Ou seja, mesmo que sua nota sem o incentivo da política seja maior do que a efetivamente observada estas não são suficientes para atingir as metas préestabelecidas fazendo com que estas escolas não consigam ganhar a bonificação. Assim, a escola não realiza esforço. As escolas que se encaixam nesse perfil serão as escolas do Grupo 3.

- $Y_{t *}>Y_{m}>Y_{t}-\mathrm{O}$ desempenho no ambiente contrafactual é maior do que a meta, então pode-se concluir que, mesmo sem o incentivo, a escola já possui uma performance maior do que a pré-estabelecida pela Secretaria Estadual de Educação e, portanto, não dispende esforço para atingi-la. Além disso pode-se dizer que a meta é fácil de ser alcançada. As escolas que se encaixam nesse perfil serão as escolas do Grupo 4.

- $Y_{m}>Y_{t}>Y_{t *}$ - A meta é adequada ou difícil porque é maior do que o desempenho em ambos os ambientes. A nota efetivamente observada é maior do que aquela atingida no ambiente contrafactual, mostrando que as escolas desse grupo efetivamente realizam esforço. As escolas que se encaixam nesse perfil serão as escolas do Grupo 5.

- $Y_{t *}>Y_{t} \geq Y_{m}-\mathrm{A}$ meta nesse caso é fácil de ser atingida, já que o desempenho nos dois ambientes é mais alto do que ela. Porém, não há esforço dispendido, já que a performance dessas escolas sem nenhum tipo de incentivo já é maior do que o efetivamente observado com a política. As escolas que se encaixam nesse perfil serão as escolas do Grupo 6.

Assim, iremos verificar o diferencial de desempenhos efetivo em t e contra factual em t; e a diferença entre a meta a ser alcançada no ano t e o desempenho contra factual em t. Se a diferença entre a meta a ser alcançada e o desempenho da escola no ambiente contra factual for menor ou igual a zero pode-se concluir que a escola não teria que realizar esforço para receber o bônus, ou seja, o desempenho que ela teria num ambiente sem política é maior ou igual à meta exigida pelo programa de bonificação. Sendo assim, o programa de incentivos não exige esforço a ser realizado por essa escola. 
Porém, se o contrário ocorre, ou seja, se a meta estabelecida é maior do que o desempenho que seria esperado num ambiente sem a política de bônus é possível inferir que essas escolas terão que se esforçar para serem contempladas pela política de bonificação.

A partir do ano de 2009 a métrica da política inclui o Índice de Qualidade das escolas, adicionando ao cálculo do recebimento do bônus o quão acima ou abaixo o desempenho dessa escola está em comparação ao desempenho médio das escolas paulistas. Então, para calcular o esforço exigido das escolas a partir desse ano, o Ym será composto pela seguinte equação:

$$
Y_{m}=I Q_{t}+I C_{t}
$$

Em que $I Q_{t}$ indica o Índice de Qualidade no ano t e $I C_{t}$ o Índice de Cumprimento da Meta no ano t.

Assim, a partir dessas estimações será possível verificar se as escolas que efetivamente precisam realizar esforço para ganhar o bônus estão mudando práticas pedagógicas, dado o desenho da política. As estimativas de esforço serão realizadas ano a ano, incluindo em seu cálculo as especificidades das Notas Técnicas de cada ano e as características socioeconômicas de cada escola nesses anos. Isso tornará possível a realização de uma análise do impacto da política de bonificação do Estado de São Paulo entre os anos de 2009 e 2013.

\subsection{Dados}

\subsubsection{Construção dos Dados}

Os dados utilizados neste estudo são provenientes de duas fontes. A primeira são os dados da Prova Brasil dos anos de 2007, 2009, 2011 e 2013 por escola e seus questionários aplicados aos diretores, professores e alunos de São Paulo, Paraná, Santa Catarina e Rio Grande do Sul. A segunda fonte de dados é o SARESP entre os anos de 2008 a 2013 analisando-se as metas e o desempenho efetivo das escolas paulistas nos anos observados. A unidade de observação dos dados será sempre a escola.

Os dados da Prova Brasil das escolas localizadas nos estados do Paraná, Santa 
Catarina e Rio Grande do Sul foram utilizadas como base para o cálculo do IDESP da mesma forma que este é calculado para as escolas paulistas que utiliza o SARESP como exame padrão para mensurar performance. Essa comparação é possível a partir de 2007 já que os dois formatos de provas passaram a adotar a mesma métrica. Além disso, as duas provas são aplicadas para as mesmas turmas de alunos do $5^{\circ}$ e $9^{\circ}$ anos fazendo com que os resultados sejam, em teoria, muito parecidos.

As duas provas são comparáveis, porém aplicadas em períodos diferentes no tempo. Como o SARESP é anual e a Prova Brasil é aplicada a cada dois anos, para os anos nos quais não há observações para a Prova Brasil (2008, 2010 e 2012) foi realizada uma interpolação das notas dos anos imediatamente anteriores e posteriores.

Com o IDESP e metas calculados para cada escola em cada ano, foi possível verificar os crescimentos e decrescimentos de desempenho que as escolas sofreram ao longo dos anos em um ambiente sem a política de bônus permitindo a construção do ambiente contrafactual para as escolas de São Paulo e a comparação com os resultados efetivos das mesmas.

As características de infraestrutura escolar e condições socioeconômicas dos alunos da escola foram coletadas nos questionários da Prova Brasil e SARESP de cada ano observado.

\subsubsection{Pareamento}

O método de Propensity Score Matching foi estimado através de um modelo Probit buscando a probabilidade de uma escola ser estadual paulista. Neste caso, qualquer escola estadual não exposta à política de bônus de São Paulo pode ser utilizada como controle.

Após o pareamento, foram selecionadas 2036 escolas para o $5^{\circ}$ ano e 3419 para o $9^{\circ}$ ano, com observações para todos os anos analisados.

Nas figuras de 1 a 4 pode-se observas as variáveis explicativas utilizadas para o pareamento que foram escolhidas na medida que possuem pouco ou nenhum impacto no fato das escolas receberem bônus. Foram utilizados os questionários da Prova Brasil de 


\section{Escolas Estaduais Paulistas - 50 ano}

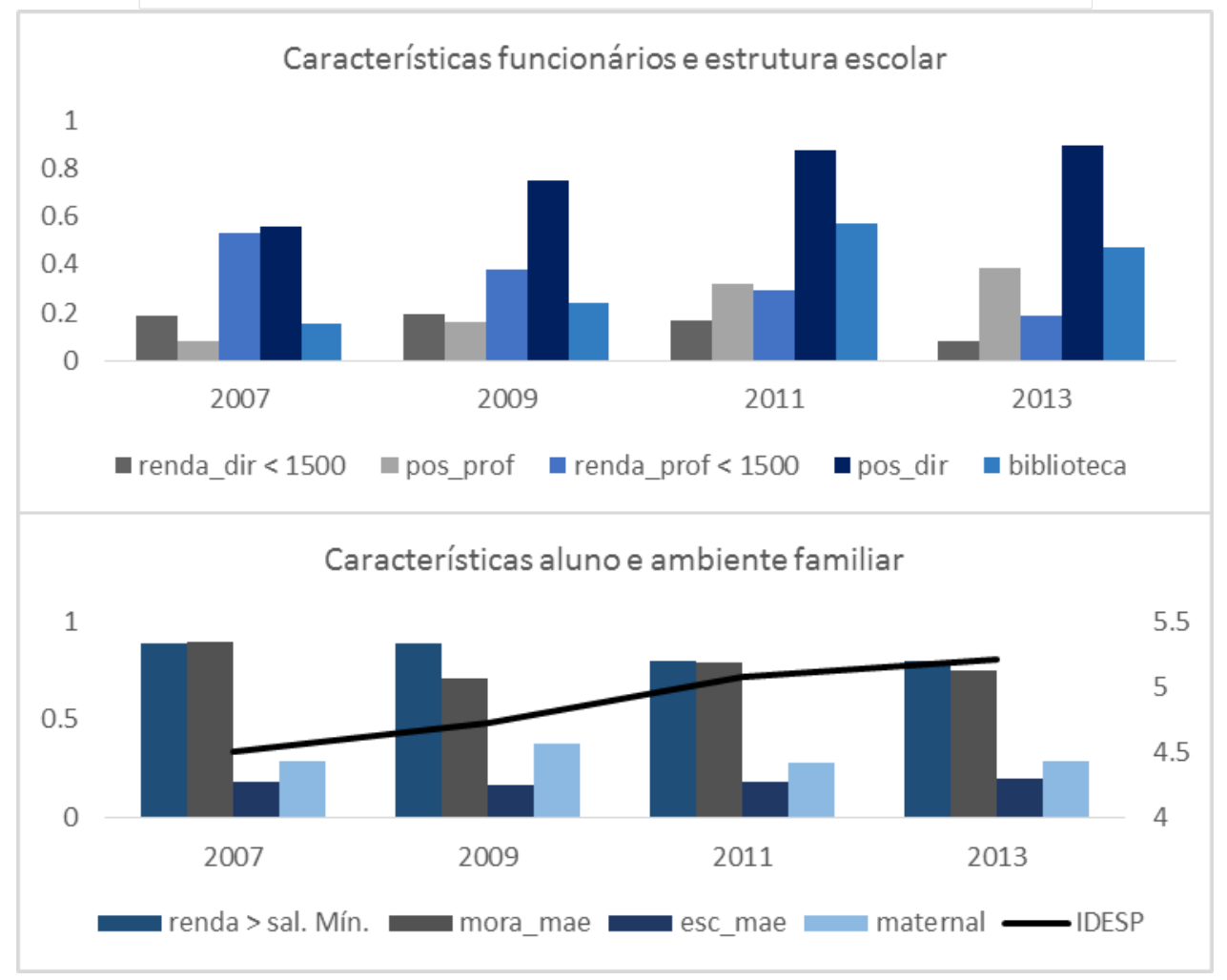

Figura 1: Variáveis explicativas utilizadas no pareamento - Escolas Estaduais Paulistas $5^{\circ}$ ano

2005 e 2007 como fonte para a criação do vetor de características das escolas e o IDESP médio de 2007 como regressor do Probit. As variáveis observadas nas figuras são antes do pareamento.

Após o pareamento, as escolas com o maior número de aderência com as escolas estaduais paulista foram as escolas estaduais localizadas no Sul do país gerando uma amostra de 2036 escolas para o $5^{\circ}$ ano (2030 escolas da região Sul foram excluídas no modelo) e 3419 escolas para o $9^{\circ}$ ano (2171 escolas excluídas). As escolas possuem o mesmo número de observações porque utilizado o pareamento do tipo exato o qual seleciona para cada escola estadual paulista uma escola estadual da região Sul com as mesmas características do vetor X e a mesma nota Y0 para o ano de 2007. Esse mesmo pareamento foi utilizado para as escolas do $9^{\circ}$ ano

As variáveis utilizadas para o pareamento são medidas na unidade de observação escola, ou seja, observam-se as características de professores, alunos e diretores por escola e não individualmente. Nas figuras abaixo são apresentados os dados referentes às escolas 


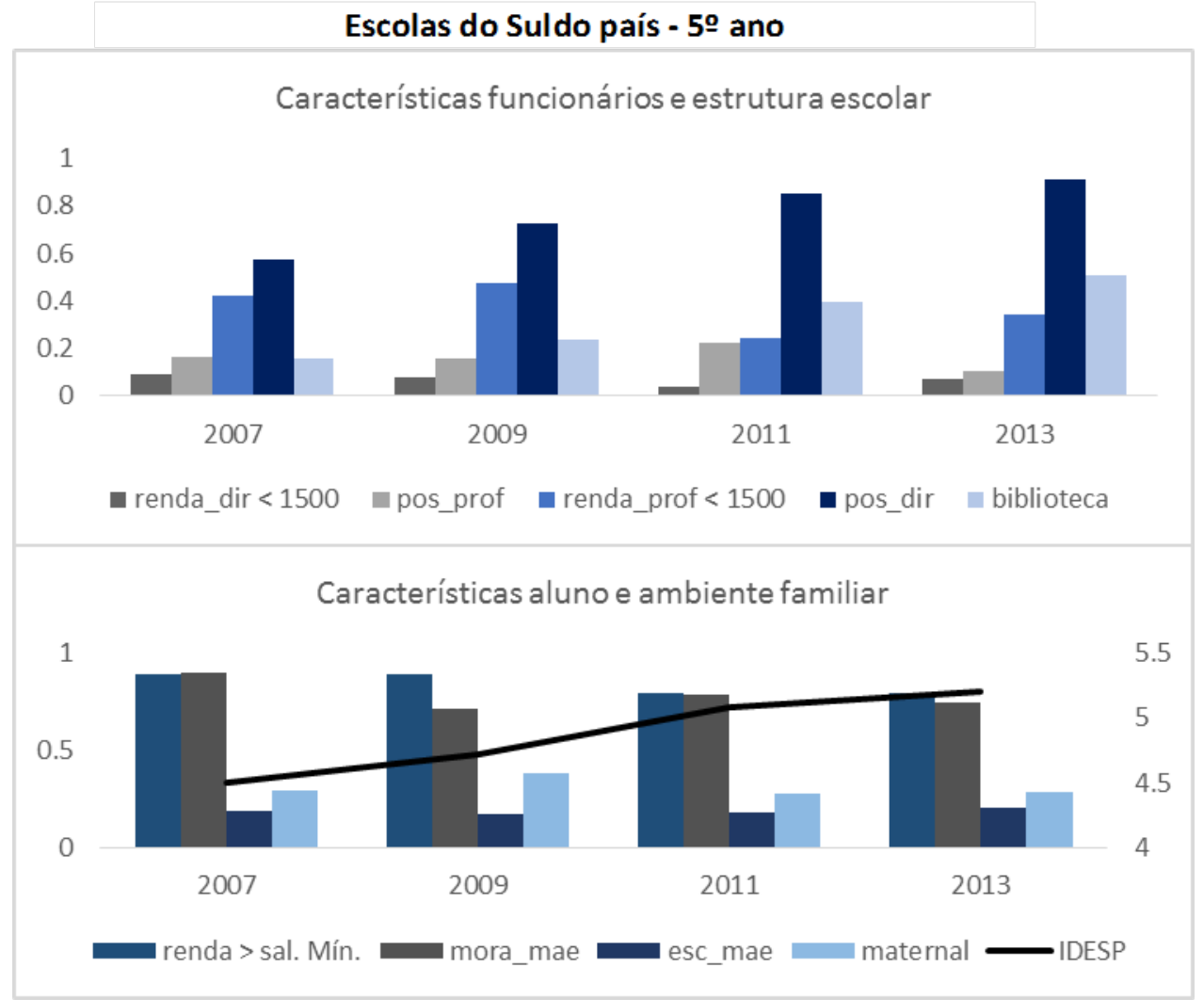

Figura 2: Variáveis explicativas utilizadas no pareamento - Escolas do Sul do país - 5o ano

\section{Escolas Estaduais Paulistas - 90 ano}

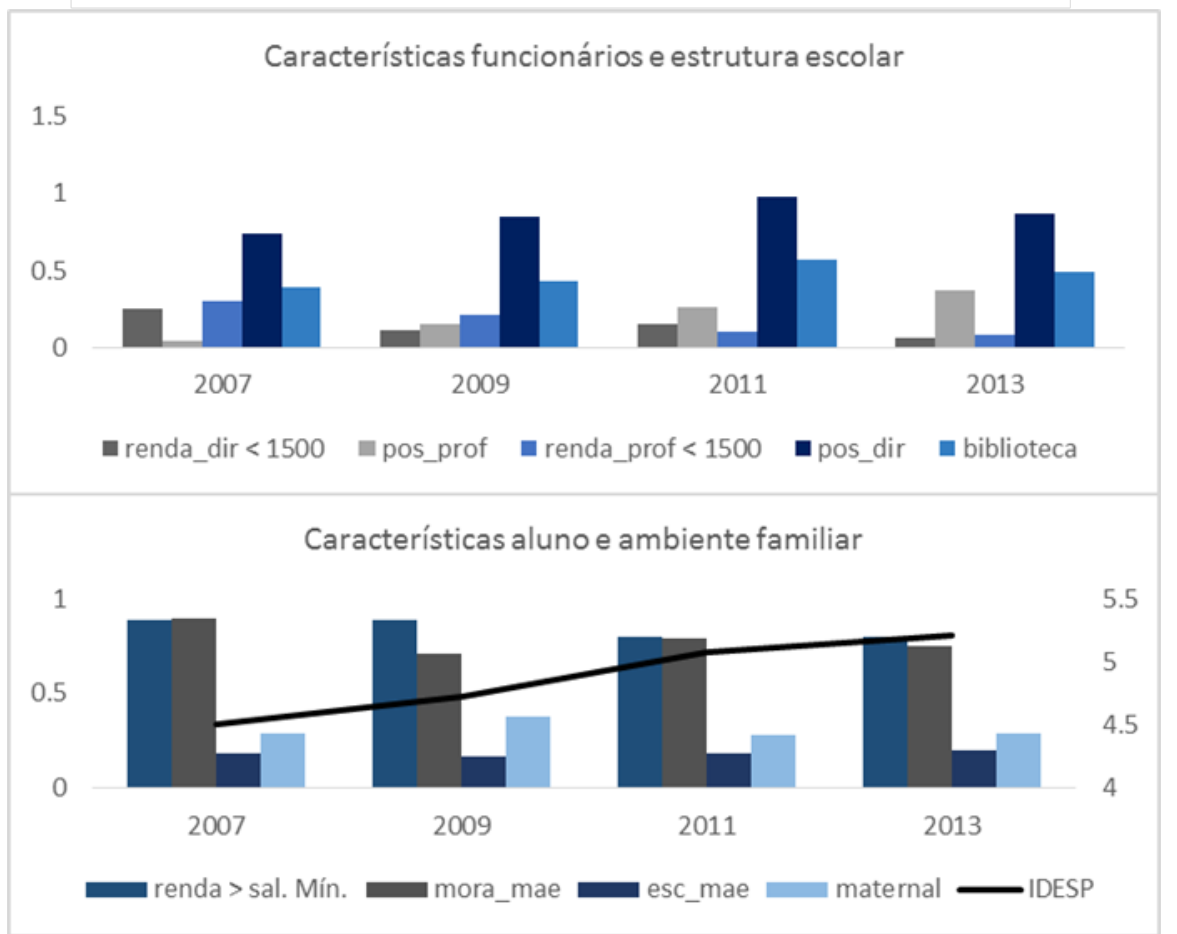

Figura 3: Variáveis explicativas utilizadas no pareamento - Escolas Estaduais Paulistas $9^{\circ}$ ano 


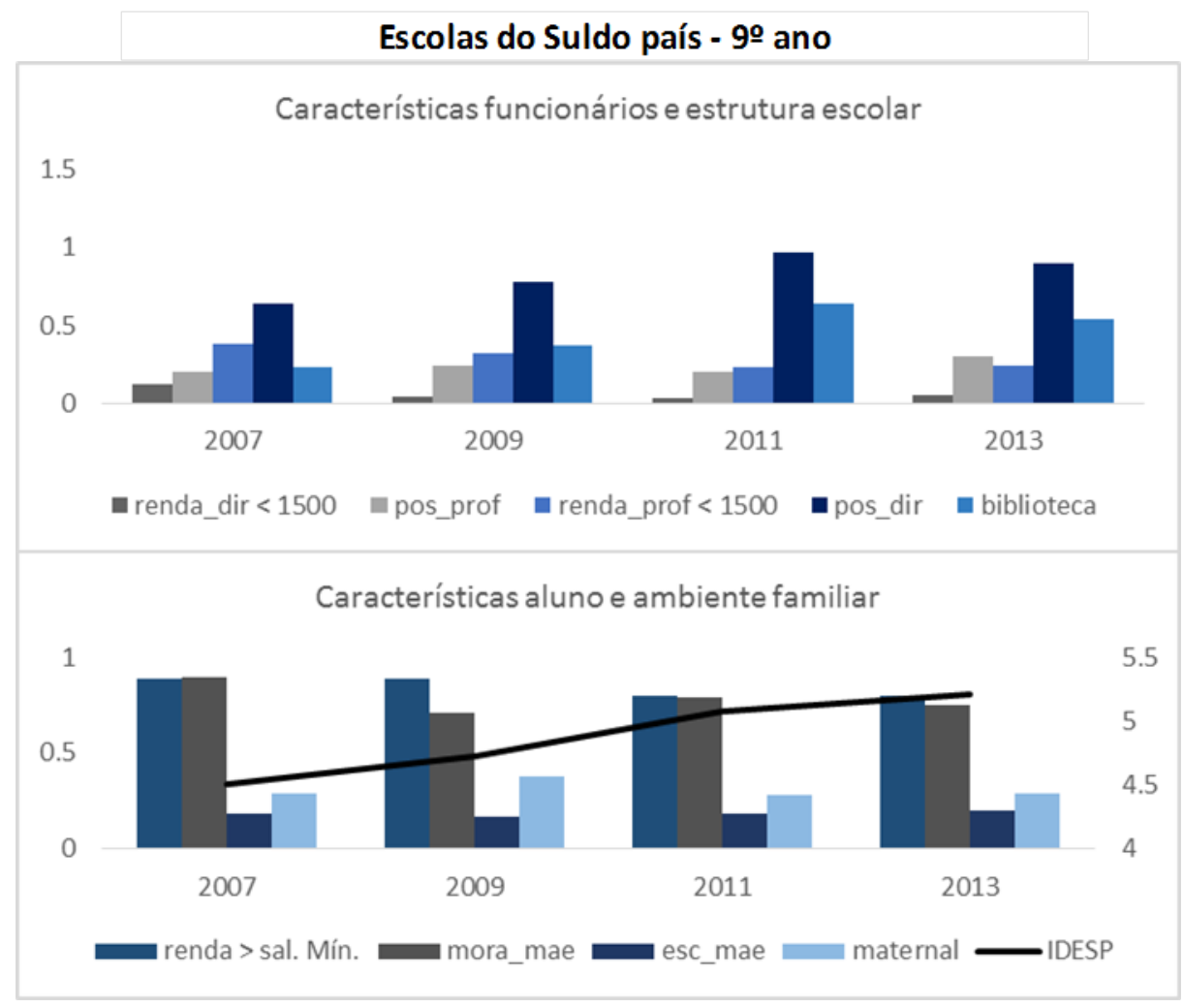

Figura 4: Variáveis explicativas utilizadas no pareamento - Escolas do Sul do país - 9o ano

de São Paulo, Paraná, Santa Catarina e Rio Grande do Sul com alunos do $5^{\circ}$ ano entre os anos de 2007 e 2013 .

Comparando-se as características entre as escolas das duas regiões percebe-se que o IDESP médio das escolas do Sul é maior do que o observado nas escolas paulistas durante os anos analisados, bem como a escolaridade de professores e diretores. Porém, nas escolas paulistas, os salários desses mesmos profissionais são maiores e as mães são mais escolarizadas. As outras variáveis são similares, como o baixo percentual de crianças que frequentaram o maternal e a proporção de escolas que possuem biblioteca.

Comparando-se as escolas de São Paulo e da região Sul para o $9^{\circ}$ ano, a média do IDESP observado para as escolas do Sul é maior do que o observado em São Paulo (mas a diferença não é tão grande quanto o observado para as escolas com alunos do $5^{\circ}$ ano). Características do professor são muito diferentes entre as duas regiões: apenas $13 \%$ dos professores das escolas paulistas possuem pós-graduação e cerca de $10 \%$ deles recebem salários menores que $\mathrm{R} \$ 1.500,00$; enquanto que $26 \%$ dos professores das escolas 
localizadas na região Sul possuem pós-graduação e $28 \%$ deles recebem salário menor que $\mathrm{R} \$ 1.500,00$.

\subsection{Análise da distribuição do bônus}

Uma boa maneira de entender o funcionamento da política é através da análise da distribuição do bônus entre as escolas estaduais de São Paulo. Uma maneira de se fazer isso é observar o número de vezes que cada escola recebeu o bônus com as características socioeconômicas que não afetam seu recebimento.

As variáveis analisadas são a porcentagem das escolas que receberam bonificação, a porcentagem de escolas localizadas no município de São Paulo, o fato da escola possuir biblioteca, a proporção de alunos que moram com a mãe, a proporção de mães de alunos que completaram pelo menos o Ensino Médio e a proporção de alunos que frequentaram o maternal (as características descritivas foram retiradas dos questionários da Prova Brasil de 2007).

Os dados analisados a seguir são uma descrição das características das escolas de acordo com o número de vezes que as mesmas receberam o bônus durante os cinco anos observados na tentativa de mensurar se o fato da escola receber ou não o bônus impacta na quantidade de esforço dispendido pelas escolas.

Tabela 4: Características das escolas do $5^{\circ}$ ano de acordo com o recebimento do bônus entre 2009 e 2013

\begin{tabular}{|c|c|c|c|c|c|c|}
\hline Quantidade & Bonificação & Município de São Paulo & Biblioteca & Alunos moram com a mãe & Mães Ensino Médio ou mais & Maternal \\
\hline 5 vezes & $34.2 \%$ & $22.5 \%$ & $54.1 \%$ & $90.9 \%$ & $41.1 \%$ & $43.7 \%$ \\
\hline 4 vezes & $28.4 \%$ & $34.5 \%$ & $49.4 \%$ & $90.0 \%$ & $35.4 \%$ & $34.7 \%$ \\
\hline 3 vezes & $11.8 \%$ & $38.9 \%$ & $47.1 \%$ & $89.5 \%$ & $34.9 \%$ & $32.7 \%$ \\
\hline 2 vezes & $13.4 \%$ & $29.3 \%$ & $39.6 \%$ & $90.1 \%$ & $36.3 \%$ & $31.8 \%$ \\
\hline $1 \mathrm{vez}$ & $9.3 \%$ & $16.4 \%$ & $32.3 \%$ & $89.2 \%$ & $36.6 \%$ & $33.4 \%$ \\
\hline Nenhuma vez & $2.8 \%$ & $33.3 \%$ & $38.6 \%$ & $89.1 \%$ & $33.4 \%$ & $33.6 \%$ \\
\hline Rede Estadual & & $29.6 \%$ & $44.1 \%$ & $89.2 \%$ & $36.0 \%$ & $35.8 \%$ \\
\hline
\end{tabular}

Fonte: Questionários e Desempenho da Prova Brasil entre 2009 e 2013

Para as escolas do $5^{\circ}$ ano (2036 observações), 34,2\% delas ganharam bônus durante todos os anos da análise da política e cerca de $28 \%$ não ganharam em apenas um dos anos; pode-se perceber que $80 \%$ das escolas expostas à política receberam alguma forma de bonificação em pelo menos quatro dos cinco anos observados. Os outros pouco mais 
de $35 \%$ se dividem entre as escolas que receberam o bônus três, duas ou apenas uma vez durante os cinco anos analisados (sendo cerca de 10\% cada) e apenas 2,8\% das escolas nunca receberam.

Comparando isso com outros programas estaduais que possuem características parecidas com o programa paulista pode-se perceber que o programa paulista tem maior quantidade de escolas que recebem o bônus do que, por exemplo, escolas estaduais de Pernambuco nas quais, segundo Ferraz e Bruns (2012) no qual cerca de 20\% das escolas recebem o bônus frequentemente e a mesma proporção de escolas receberam o bônus em poucas ou quase nenhuma oportunidade.

Tentando entender melhor porque a distribuição tem esse comportamento para as escolas do $5^{\circ}$ ano, podem-se analisar características dessas escolas bem as de alunos e pais de alunos.

Pensando na localização das escolas, grande parte daquelas que receberam o bônus em muitos ou em alguns dos anos da exposição da política se localizam no interior do Estado de São Paulo. Característica também observada nas escolas que nunca receberam o bônus.

Apesar das características descritivas das escolas serem muito parecidas pode-se perceber que nas escolas com menor índice de recebimento do bônus a proporção de mães que completaram pelo menos o Ensino Médio e de alunos que fizeram o maternal é menor, com diferenças expressivas entre essas proporções quando se comparam as escolas que receberam bônus todos os anos e aquelas que nunca receberam.

Tabela 5: Características das escolas do $9^{\circ}$ ano de acordo com o recebimento do bônus entre 2009 e 2013

\begin{tabular}{|c|c|c|c|c|c|c|}
\hline Quantidade & Bonificação & Município de São Paulo & Biblioteca & Alunos moram com a mãe & Mães Ensino Médio ou mais & Maternal \\
\hline 5 vezes & $42.7 \%$ & $13.2 \%$ & $40.1 \%$ & $90.5 \%$ & $35.8 \%$ & $45.9 \%$ \\
\hline 4 vezes & $29.3 \%$ & $19.4 \%$ & $32.3 \%$ & $89.6 \%$ & $35.7 \%$ & $41.7 \%$ \\
\hline 3 vezes & $12.5 \%$ & $18.1 \%$ & $32.4 \%$ & $89.3 \%$ & $35.8 \%$ & $41.2 \%$ \\
\hline 2 vezes & $9.3 \%$ & $15.4 \%$ & $30.3 \%$ & $89.7 \%$ & $35.9 \%$ & $40.7 \%$ \\
\hline $1 \mathrm{vez}$ & $4.6 \%$ & $18.2 \%$ & $29.5 \%$ & $89.8 \%$ & $34.6 \%$ & $40.1 \%$ \\
\hline Nenhuma vez & $1.4 \%$ & $16.4 \%$ & $10.9 \%$ & $91.0 \%$ & $33.2 \%$ & $39.8 \%$ \\
\hline Rede Estadual & & $16.5 \%$ & $28.5 \%$ & $90.8 \%$ & $35.7 \%$ & $41.3 \%$ \\
\hline
\end{tabular}

3814 escolas

Fonte: Questionários e Desempenho da Prova Brasil entre 2009 e 2013

Fazendo-se a mesma análise para os alunos do $9^{\circ}$ ano, percebem-se diferenças 
enormes no desempenho dos alunos e na distribuição do incentivo. São observadas 3814 escolas. Mais de 40\% delas receberam o bônus todos os anos, cerca de $30 \%$ recebeu o bônus em quatro dos cinco anos observados e 1,4\% nunca recebeu. Ou seja, se adicionarmos as escolas que receberam bônus três vezes em cinco anos, mais de $84 \%$ das escolas receberam algum tipo de bonificação na maior parte dos anos analisados.

Em relação à localidade das escolas, a grande maioria das escolas de sucesso se encontra no interior do estado. Apenas 13,2\% daquelas que recebem o bônus todos os anos ficam no município de São Paulo.

Percebe-se, também, que escolas que nunca receberam o bônus possuem percentual mais baixos de mães com pelo menos o Ensino Médio completo, biblioteca e de alunos que fizeram o maternal.

Nesta seção foi descrito o perfil de recebimento do bônus entre as escolas no Estado de São Paulo. Na apuração dos resultados esse perfil será relacionado com a realização efetiva de esforço e as características socioeconômicas de cada escola a fim de se apurar qual o papel desses elementos no dispêndio ou não de esforço.

\section{Resultados}

No presente capítulo serão apresentados a estimação do desempenho das escolas paulistas em ambiente contrafactual para a comparação entre o desempenho dessas mesmas escolas nos dois ambientes e a distribuição dos bônus entre as escolas estaduais de São Paulo relacionado com o esforço despendido pelas mesmas.

\subsection{Construção do Ambiente Contrafactual}

Para a construção do ambiente contrafactual, foram utilizadas as notas da Prova Brasil das escolas estaduais do Paraná, Santa Catarina e Rio Grande do Sul entre os anos de 2007 e 2013; além das respostas de professores, diretores e alunos para a construção do vetor de características de cada escola. Para o vetor de características foram utilizadas 
as proporções de professores e diretores que possuem pós-graduação e salários menores que $\mathrm{R} \$ 1500,00$; proporção de alunos que moram com as mães, proporção de alunos que frequentaram o maternal; proporção de mães de alunos que completaram pelo menos o Ensino Médio e se a escola possui ou não biblioteca.

Através do cálculo do IDESP, foi possível verificar o desempenho das escolas fora do Estado de São Paulo caso suas notas fossem utilizadas para a distribuição de bônus e, com esses desempenhos, estimar os parâmetros para a construção do ambiente contrafactual utilizando a equação (9).

Com a estimação de $\alpha, \beta$ e $\gamma$ foi possível projetar o desempenho das escolas paulistas em um ambiente no qual a política não existia criando a variável $\mathrm{Y}^{*}$ que indica a performance das escolas sem a política de bonificação.

Para os anos nos quais a Prova Brasil não é realizada (2008, 2010 e 2012) foi realizada uma interpolação linear entre o desempenho dos anos imediatamente anterior e posterior.

Abaixo nas figuras 5 e 6 podem ser observadas a dispersão do IDESP em cada ano (entre 2009 e 2013) comparando-se as notas efetivamente observadas e aquelas que os alunos teriam em um ambiente contrafactual.

Para as escolas do $5^{\circ}$ ano pode-se perceber que as notas dos ambientes contrafactuais são relativamente maiores, em média, do que as notas no ambiente de bonificação com notas mais concentradas no primeiro ano do programa e muito dispersas nos anos seguintes.

O mesmo pode ser observado nas notas das escolas do $9^{\circ}$ ano que, como observado nas seções anteriores, possuem desempenho absoluto menor do que as escolas com alunos do $5^{\circ}$ ano. As notas são extremamente concentradas no início da política e também se dispersam com o passar dos anos (com exceção do ano de 2012).

Esta análise é importante na medida em que mostra o comportamento diverso existente entre as escolas durante um mesmo ano. Para os alunos do $5^{\circ}$ e $9^{\circ}$ ano, observamse as seguintes dispersões entre 2009 e 2013 acima exemplificadas. 

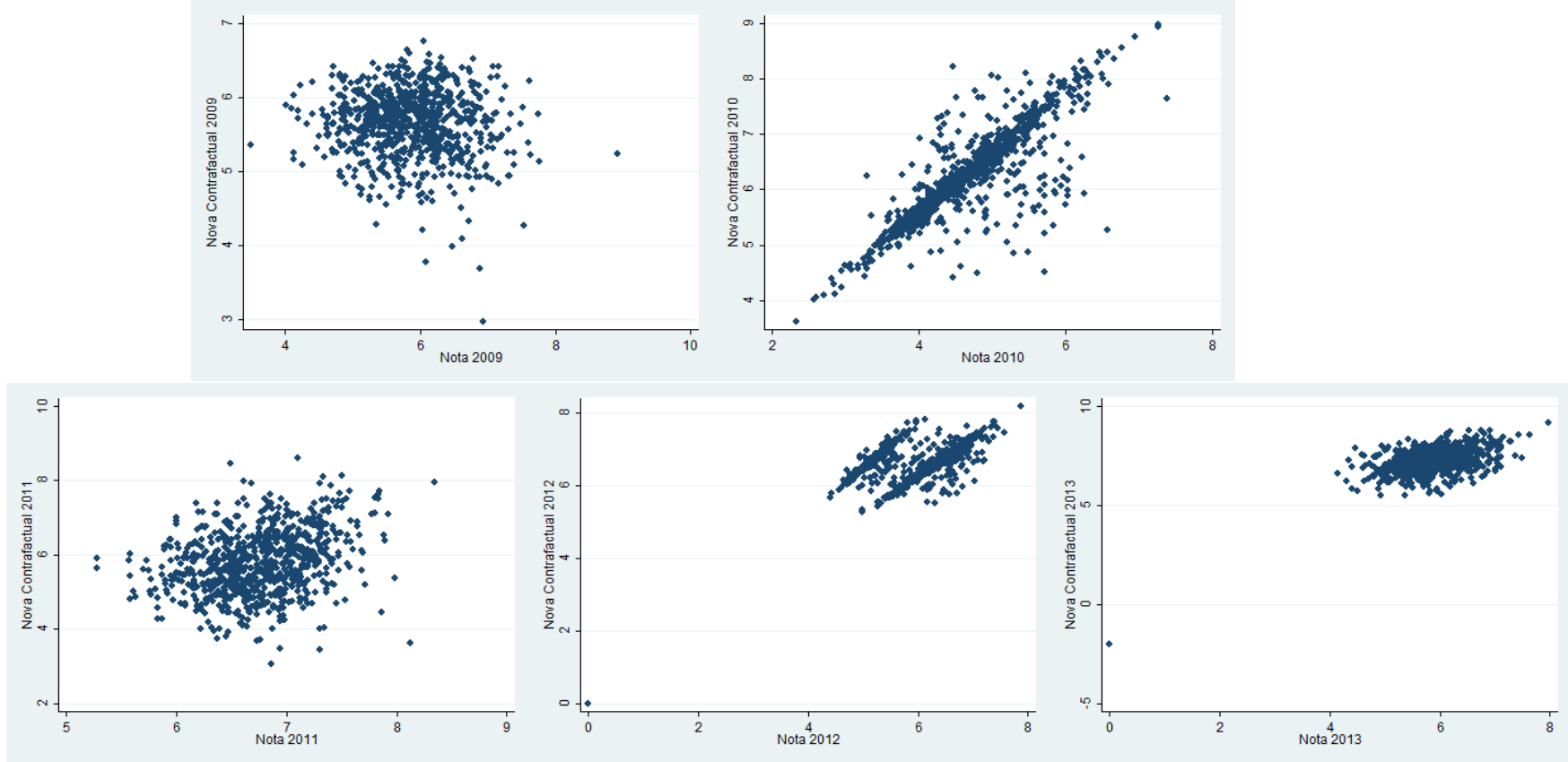

Figura 5: Dispersão de Notas nos ambientes contrafactual e efetivo - $5^{\circ}$ ano
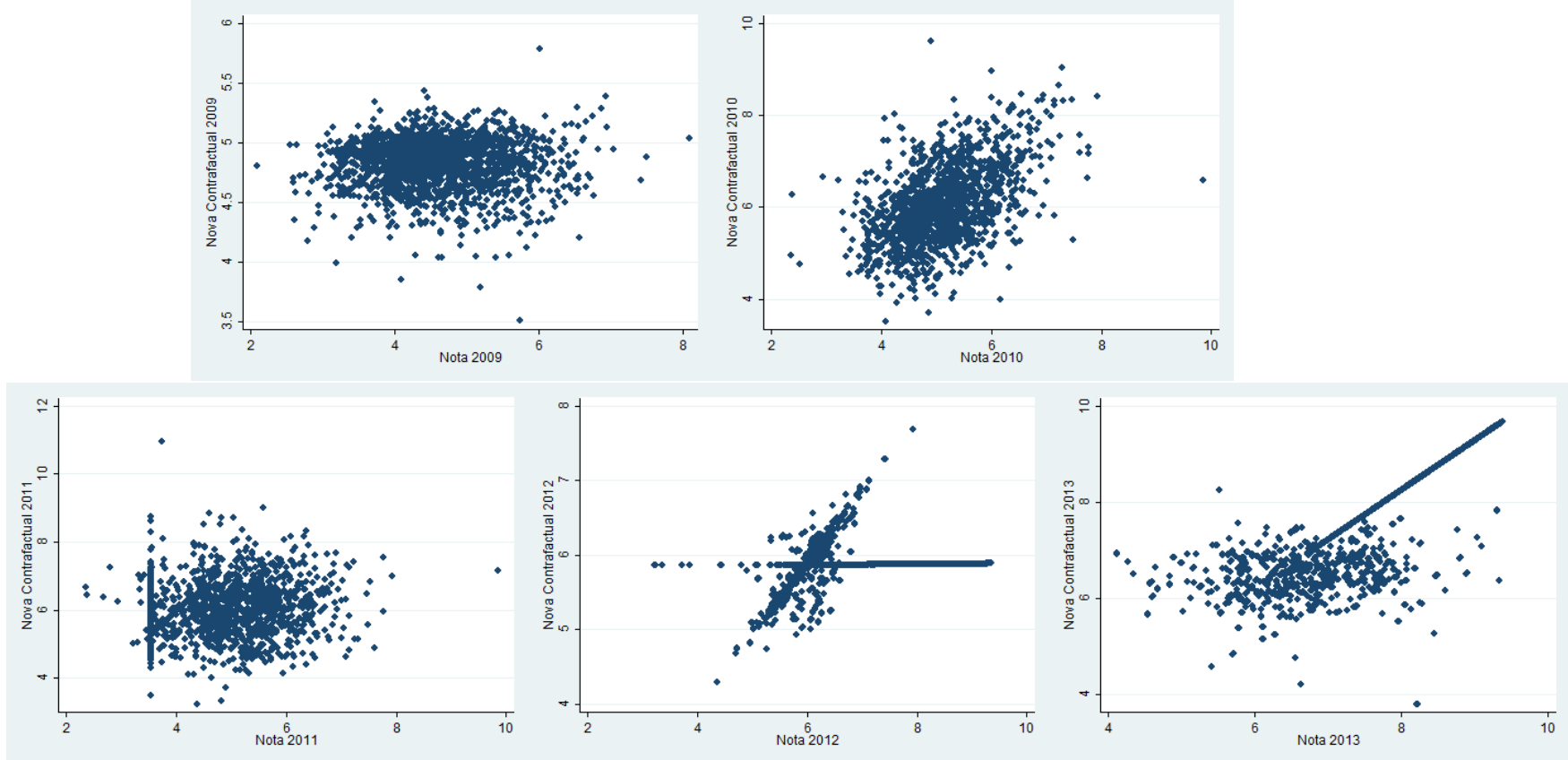

Figura 6: Dispersão de Notas nos ambientes contrafactual e efetivo - $9^{\circ}$ ano 


\subsection{Análise de Esfoço}

Para a análise do impacto do esforço foi utilizado os diferenciais de desempenho entre os dois ambientes e o quão distantes as escolas paulistas estariam das metas préestabelecidas em um ambiente no qual a política de bonificação não existisse.

De acordo com a divisão da realização de esforço nos seis grupos listados na Metodologia, pode-se observar nas duas tabelas abaixo a proporção de escolas que possuem desempenho efetivo no ano t maior que o desempenho no ambiente contrafactual e também a proporção de escolas nas quais a meta pré-estabelecida pela Secretaria de Educação do Estado de São Paulo é maior do que o desempenho no ambiente contrafactual.

\begin{tabular}{|c|c|c|c|c|c|c|c|c|c|c|c|c|c|c|c|}
\hline & & 2009 & & & 2010 & & & 2011 & & & 2012 & & & 2013 & \\
\hline Grupo & Prop. & Esforço & Bônus & Prop. & Esforço & Bônus & Prop. & Esforço & Bônus & Prop. & Esforço & Bônus & Prop. & Esforço & Bônus \\
\hline 1 & $0.17 \%$ & Bastante & $100.0 \%$ & $5.01 \%$ & Bastante & $94.8 \%$ & $3.73 \%$ & Bastante & $50.0 \%$ & $0.17 \%$ & Bastante & $89.2 \%$ & $8.63 \%$ & Bastante & $66.2 \%$ \\
\hline 2 & $18.51 \%$ & Pouco & $60.8 \%$ & $4.55 \%$ & Pouco & $50.9 \%$ & $6.79 \%$ & Pouco & $55.1 \%$ & $18.51 \%$ & Pouco & $56.2 \%$ & $7.93 \%$ & Pouco & $51.9 \%$ \\
\hline 3 & $0.03 \%$ & Bastante & $100.0 \%$ & $0.03 \%$ & Bastante & $100.0 \%$ & $0.03 \%$ & Bastante & $100.0 \%$ & $0.03 \%$ & Bastante & $100.0 \%$ & $0.00 \%$ & Bastante & $100.0 \%$ \\
\hline 4 & $31.20 \%$ & Pouco & $57.5 \%$ & $33.47 \%$ & Pouco & $50.6 \%$ & $35.28 \%$ & Pouco & $53.5 \%$ & $31.20 \%$ & Pouco & $52.3 \%$ & $22.22 \%$ & Pouco & $51.5 \%$ \\
\hline 5 & $24.06 \%$ & Médio & $39.5 \%$ & $27.89 \%$ & Médio & $41.6 \%$ & $28.15 \%$ & Médio & $32.2 \%$ & $26.21 \%$ & Médio & $48.2 \%$ & $28.36 \%$ & Médio & $53.2 \%$ \\
\hline 6 & $26.03 \%$ & Pouco & $51.1 \%$ & $29.05 \%$ & Pouco & $63.0 \%$ & $26.02 \%$ & Pouco & $66.1 \%$ & $32.36 \%$ & Pouco & $67.0 \%$ & $32.86 \%$ & Pouco & $71.2 \%$ \\
\hline
\end{tabular}

Fonte: Desempenho efetivo utilizando a Prova Brasil e desempenho contrafactual

Para o $5^{\circ}$ ano, observa-se uma concentração maior das escolas no Grupo 4, ou seja, escolas com metas fáceis que dispendem pouco ou nenhum esforço. E, analisando-se a proporção dessas que efetivamente o recebem, percebe-se que em sua grande maioria outras variáveis que não apenas o esforço definem o recebimento do incentivo por essas escolas.

Além disso, pode-se perceber uma maior concentração de escolas nos grupos que precisam dispender pouco esforço para atingir as metas (ou seja, que a meta pré-estabelecida em todos os anos seja maior ou igual ao desempenho atingido no ambiente contrafactual), mas nem todas elas conseguem receber o bônus, apesar da grande maioria receber. Por outro lado, nos casos em que as escolas precisam realizar muito esforço os casos de sucesso são quase que unânimes. Pode-se concluir que, para as escolas dos grupos 1 e 3, a política realmente atinge o seu fim que é fazer com que as escolas melhorem o desempenho a cada ano a fim de manter a qualidade do ensino e, consequentemente, o recebimento do bônus.

Para o caso no qual as escolas precisam fazer um esforço médio (esforço esse que 
pode ser maior ou menor dependendo do quão maior é o desempenho efetivo sobre o desempenho contrafactual), menos da metade recebem a bonificação.

Tabela 7: Análise de Esforço observado para as escolas do $9^{\circ}$ ano utilizando o diferencial entre o desemepnho efetivo e contrafactual

\begin{tabular}{|c|c|c|c|c|c|c|c|c|c|c|c|c|c|c|c|}
\hline \multirow[b]{2}{*}{ Grupo } & \multicolumn{3}{|c|}{2009} & \multicolumn{3}{|c|}{2010} & \multicolumn{3}{|c|}{2011} & \multicolumn{3}{|c|}{2012} & \multicolumn{3}{|c|}{2013} \\
\hline & Prop. & Esforço & Bônus & Prop. & Esforço & Bônus & Prop. & Esforço & Bônus & Prop. & Esforço & Bônus & Prop. & Esforço & Bônus \\
\hline 1 & $1.33 \%$ & Bastante & $91.6 \%$ & $0.89 \%$ & Bastante & $88.3 \%$ & $18.13 \%$ & Bastante & $65.1 \%$ & $16.29 \%$ & Bastante & $71.2 \%$ & $9.48 \%$ & Bastante & $65.2 \%$ \\
\hline 2 & $36.99 \%$ & Pouco & $65.7 \%$ & $1.56 \%$ & Pouco & $59.6 \%$ & $35.26 \%$ & Pouco & $62.2 \%$ & $6.36 \%$ & Pouco & $100.0 \%$ & $3.96 \%$ & Pouco & $100.0 \%$ \\
\hline 3 & $0.23 \%$ & Bastante & $100.0 \%$ & $0.11 \%$ & Bastante & $100.0 \%$ & $0.11 \%$ & Bastante & $100.0 \%$ & $0.11 \%$ & Bastante & $100.0 \%$ & $0.33 \%$ & Bastante & $100.0 \%$ \\
\hline 4 & $34.09 \%$ & Pouco & $89.0 \%$ & $55.77 \%$ & Pouco & $56.1 \%$ & $16.90 \%$ & Pouco & $66.3 \%$ & $50.31 \%$ & Pouco & $61.4 \%$ & $59.23 \%$ & Pouco & $58.6 \%$ \\
\hline 5 & $11.12 \%$ & Médio & $44.3 \%$ & $25.89 \%$ & Médio & $39.1 \%$ & $12.29 \%$ & Médio & $41.2 \%$ & $11.10 \%$ & Médio & $47.3 \%$ & $10.14 \%$ & Médio & $36.1 \%$ \\
\hline 6 & $16.24 \%$ & Pouco & $64.3 \%$ & $15.77 \%$ & Pouco & $65.3 \%$ & $17.31 \%$ & Pouco & $68.2 \%$ & $15.84 \%$ & Pouco & $68.9 \%$ & $16.86 \%$ & Pouco & $71.3 \%$ \\
\hline
\end{tabular}

Fonte: Desempenho efetivo utilizando a Prova Brasil e desempenho contrafactual

Para as escolas de $9^{\circ}$ ano, as conclusões são muito parecidas com as escolas de $5^{\circ}$ ano, com proporções de recebimento do bônus distintas. Pode-se verificar que os grupos 2 e 4 se revezam nos anos observados como a maioria dos casos. Com isso pode-se concluir que a meta é fácil para grande parte das escolas, fazendo com que o esforço dispendido seja muito baixo.

Com a percepção de esforço definida na metodologia pode-se verificar a relação entre essa e o recebimento do bônus entre os anos de 2009 e 2013.

Tabela 8: Percepção de esforço e recebimento do bônus para as escolas do $5^{\circ}$ ano

\begin{tabular}{lccccc}
\hline \hline Recebimento do bônus & 2009 & 2010 & 2011 & 2012 & 2013 \\
\hline 5 vezes & $41.6 \%$ & $42.3 \%$ & $66.4 \%$ & $63.0 \%$ & $43.8 \%$ \\
4 vezes & $28.4 \%$ & $29.5 \%$ & $42.3 \%$ & $40.0 \%$ & $30.6 \%$ \\
3 vezes & $25.3 \%$ & $27.1 \%$ & $44.3 \%$ & $37.1 \%$ & $27.1 \%$ \\
2 vezes & $20.4 \%$ & $23.2 \%$ & $36.0 \%$ & $36.4 \%$ & $23.6 \%$ \\
1 vez & $29.4 \%$ & $31.9 \%$ & $37.4 \%$ & $37.4 \%$ & $31.9 \%$ \\
Nenhuma & $8.8 \%$ & $8.8 \%$ & $12.3 \%$ & $12.3 \%$ & $8.8 \%$ \\
\hline
\end{tabular}

Fonte: Dados SARESP entre 2008 e 2012

Para as escolas do $5^{\circ}$ ano percebe-se que quanto maior o número de vezes que as escolas receberam o bônus durante os anos analisados, maior é a proporção de escolas que realizam esforço para atingir a meta. Em escolas cujo recebimento do bônus foi observado uma ou nenhuma vez, a medida que indica esforço é pouco observada.

A mesma análise pode ser feita para as escolas com alunos de $9^{\circ}$ ano, porém com proporções ainda menores do que as observadas para o $5^{\circ}$ ano. 
Tabela 9: Percepção de esforço e recebimento do bônus para as escolas do $9^{\circ}$ ano

\begin{tabular}{lccccc}
\hline \hline Recebimento do bônus & 2009 & 2010 & 2011 & 2012 & 2013 \\
\hline 5 vezes & $37.3 \%$ & $37.9 \%$ & $59.5 \%$ & $56.5 \%$ & $39.2 \%$ \\
4 vezes & $25.5 \%$ & $26.4 \%$ & $37.9 \%$ & $35.8 \%$ & $27.4 \%$ \\
3 vezes & $22.7 \%$ & $24.3 \%$ & $39.7 \%$ & $33.3 \%$ & $24.3 \%$ \\
2 vezes & $18.3 \%$ & $20.8 \%$ & $32.3 \%$ & $32.6 \%$ & $21.2 \%$ \\
1 vez & $26.4 \%$ & $28.6 \%$ & $33.5 \%$ & $33.5 \%$ & $28.6 \%$ \\
Nenhuma & $7.9 \%$ & $7.9 \%$ & $11.0 \%$ & $11.0 \%$ & $7.9 \%$ \\
\hline
\end{tabular}

Fonte: Dados SARESP entre 2008 e 2012

Portanto, percebe-se uma efetiva mudança de comportamento, mesmo que pequena, nas escolas do $5^{\circ}$ ano as quais, em alguns anos, despendem grande esforço possuindo performances maiores do que aquelas que poderiam ser observadas caso a política não existisse.

Porém compreende-se que, em todos os anos e séries observados, a meta préestabelecida, na média, nunca é maior do o desempenho no ambiente contrafactual; fazendo com que o ambiente socioeconômico no qual a escola está inserida tenha grande papel na definição do recebimento do bônus.

Esses resultados conversam com a análise de Ferraz e Bruns (2012) na medida em que o recebimento do bônus se torna mais difícil para as escolas cujo desempenho está muito abaixo da meta pré-estabelecida a cada ano. Quanto mais longe o desempenho da escola fica da meta no ano $\mathrm{X}$, mais difícil será para a mesma atingi-la no ano $X+1$. O contrário é observado para as escolas com desempenho próximo ou maior que a meta.

Nos casos da realização do esforço percebe-se que as escolas que já possuem alto desempenho no ambiente contrafactual, recebem facilmente o bônus, despendendo pouquíssimo ou nenhum esforço dado o incentivo da política. Poucas escolas (dentre as analisadas) realizam um esforço efetivamente grande para que o incentivo financeiro da política seja determinante para a superação de outras deficiências que não sejam apenas o desempenho escolar dos alunos.

Assim, escolas com alto desempenho no ambiente contrafactual quase que inteiramente recebem a bonificação no ambiente efetivo, mostrando que a política beneficia 
mais as escolas com melhor qualidade de ensino e, provavelmente, melhores condições socioeconômicas e estruturais.

\section{Análise de Robustez}

Uma das críticas que pode ser feita à escolha das variáveis que compõem as características socioeconômicas nas quais as escolas estão inseridas é que se mudássemos as variáveis analisadas, os resultados poderiam ser diferentes.

Para checar a robustez dos resultados encontrados, foram utilizadas técnicas e variáveis alternativas para verificar se os resultados encontrados são robustos a alterações nessas especificações.

Seguindo Hirano, Imbens e Ridder (2003) a equação (9) foi reestimada utilizandose outras variáveis como vetor de características das escolas estaduais paulistas e de outros estados. A escolha dessas novas variáveis para o teste de robustez foi feita baseando-se na mesma premissa descrita na Metodologia: as variáveis escolhidas não poderiam ser influenciadas pela política.

Utilizando a mesma fonte de dados, ou seja, a resposta de alunos, professores, diretores e pais de alunos aos questionários da Prova Brasil dos anos de 2005 e 2007, foram coletadas as seguintes variáveis:

- Pai frequentou pelo menos o Ensino Médio

- Se o aluno mora com o pai

- Professores com mais de 5 anos de experiência no cargo

- Diretores com mais de 5 anos de experiência no cargo

- Família possui carro

- Família vive em habitação com mais de 4 cômodos

- Escola possui mais de 10 computadores para uso dos alunos 
Além da estimação da equação (9) foi realizado o Pareamento por Escore de Propensão Exato a fim de encontrar as escolas da região Sul do país mais parecidas com as escolas paulistas para a construção do ambiente contrafactual.

Com os novos parâmetros encontrados com a equação (9) podem-se definir os seguintes desempenhos médios para os alunos de $5^{\circ}$ e $9^{\circ}$ anos os dois ambientes analisados (ambiente de desempenho efetivo e ambiente contrafactual):

Tabela 10: Desempenho Contrafactual $5^{\circ}$ ano - estatísticas descritivas

\begin{tabular}{lcc}
\hline Variáveis & Média & Desvio Padrão \\
\hline Nota 2009 & 5.80 & 0.68 \\
Contrafactual 2009 & 5.47 & 0.46 \\
Nota 2010 & 5.60 & 0.61 \\
Contrafactual 2010 & 6.25 & 0.86 \\
Nota 2011 & 6.16 & 0.81 \\
Contrafactual 2011 & 6.56 & 1.21 \\
Nota 2012 & 5.44 & 1.12 \\
Contrafactual 2012 & 4.69 & 2.12 \\
Nota 2013 & 5.48 & 1.38 \\
Contrafactual 2013 & 5.69 & 1.24 \\
\hline 2036 observações & &
\end{tabular}

Tabela 11: Desempenho Contrafactual $9^{\circ}$ ano - estatísticas descritivas

\begin{tabular}{lcc}
\hline Variáveis & Média & Desvio Padrão \\
\hline Nota 2009 & 4.60 & 0.78 \\
Contrafactual 2009 & 4.32 & 0.23 \\
Nota 2010 & 5.13 & 0.83 \\
Contrafactual 2010 & 5.31 & 1.02 \\
Nota 2011 & 5.52 & 0.98 \\
Contrafactual 2011 & 5.51 & 1.03 \\
Nota 2012 & 5.94 & 1.06 \\
Contrafactual 2012 & 5.40 & 1.39 \\
Nota 2013 & 5.92 & 1.19 \\
Contrafactual 2013 & 5.35 & 1.55 \\
\hline 3419 observações & &
\end{tabular}

Comparando-se com o observado anteriormente, percebe-se um alinhamento nos resultados sendo os últimos menores do que os observados com o vetor de características $\mathrm{X}$ original. Ainda podem ser observados valores absolutos menores para os alunos que frequentam as escolas de $9^{\circ}$ ano quando comparados às escolas com alunos do $5^{\circ}$ ano. 
Quando a análise de refere à mensuração do esforço, observam-se resultados essencialmente diferentes apenas para as escolas de $5^{\circ}$ ano. Em todos os anos da análise, ocorre o caso 4: $Y_{t *}>Y_{m}>Y_{t}$. Ou seja, a nota no ambiente contrafactual é maior do que a meta pré-estabelecida e o desempenho efetivo, fazendo com que seja mais difícil que essas escolas despendam muito esforço para atingir a meta. Porém, não se pode afirmar com certeza se as notas efetivamente observadas são maiores do que as metas préestabelecidas. Observando-se a porcentagem de escolas que receberam o bônus durante os anos analisados pode-se dizer que, em média, essas são maiores.

Tabela 12: Porcentagem de escolas que receberam o bônus

$$
5^{\circ} \text { ano } \quad 9^{\circ} \text { ano }
$$

\begin{tabular}{cccccc}
\hline Ano & Yt>Yt* & Ym>Yt* & Ano & Yt>Yt* & Ym>Yt* \\
\hline 2009 & $42.0 \%$ & $30.7 \%$ & 2009 & $31.0 \%$ & $10.8 \%$ \\
2010 & $19.1 \%$ & $32.5 \%$ & 2010 & $7.6 \%$ & $5.9 \%$ \\
2011 & $42.2 \%$ & $32.7 \%$ & 2011 & $19.6 \%$ & $5.5 \%$ \\
2012 & $35.4 \%$ & $38.8 \%$ & 2012 & $14.3 \%$ & $7.0 \%$ \\
2013 & $10.7 \%$ & $34.1 \%$ & 2013 & $13.3 \%$ & $7.7 \%$ \\
\hline
\end{tabular}

Já quando se analisa a percepção de esforço das escolas levando em consideração a quantidade de vezes que essas receberam o bônus tem-se os seguintes resultados:

Tabela 13: Percepção de esforço e recebimento do bônus para análise de robustez - $5^{\circ}$

ano

\begin{tabular}{|c|c|c|c|c|c|c|c|c|c|c|}
\hline \multirow{2}{*}{ Recebimento do bônus } & \multicolumn{2}{|c|}{2009} & \multicolumn{2}{|c|}{2010} & \multicolumn{2}{|c|}{2011} & \multicolumn{2}{|c|}{2012} & \multicolumn{2}{|c|}{2013} \\
\hline & Não Esforço & Esforço & Não Esforço & Esforço & Não Esforço & Esforço & Não Esforço & Esforço & Não Esforço & Esforço \\
\hline 5 vezes & $59.9 \%$ & $40.1 \%$ & $58.8 \%$ & $41.2 \%$ & $35.3 \%$ & $64.7 \%$ & $40.7 \%$ & $59.3 \%$ & $61.0 \%$ & $39.0 \%$ \\
\hline 4 vezes & $73.4 \%$ & $26.6 \%$ & $71.9 \%$ & $28.1 \%$ & $60.7 \%$ & $39.3 \%$ & $66.0 \%$ & $34.0 \%$ & $75.4 \%$ & $24.6 \%$ \\
\hline 3 vezes & $76.6 \%$ & $23.4 \%$ & $74.3 \%$ & $25.7 \%$ & $58.6 \%$ & $41.4 \%$ & $69.2 \%$ & $30.8 \%$ & $79.1 \%$ & $20.9 \%$ \\
\hline 2 vezes & $81.6 \%$ & $18.4 \%$ & $78.3 \%$ & $21.7 \%$ & $67.3 \%$ & $32.7 \%$ & $70.0 \%$ & $30.0 \%$ & $82.9 \%$ & $17.1 \%$ \\
\hline $1 \mathrm{vez}$ & $72.3 \%$ & $27.7 \%$ & $69.4 \%$ & $30.6 \%$ & $65.9 \%$ & $34.1 \%$ & $68.8 \%$ & $31.2 \%$ & $73.9 \%$ & $26.1 \%$ \\
\hline Nenhuma & $93.6 \%$ & $6.4 \%$ & $93.0 \%$ & $7.0 \%$ & $92.3 \%$ & $7.7 \%$ & $96.5 \%$ & $3.5 \%$ & $92.0 \%$ & $8.0 \%$ \\
\hline
\end{tabular}

Tabela 14: Percepção de esforço e recebimento do bônus para análise de robustez - $9^{\circ}$ ano

\begin{tabular}{|c|c|c|c|c|c|c|c|c|c|c|}
\hline \multirow{2}{*}{ Recebimento do bônus } & \multicolumn{2}{|c|}{2009} & \multicolumn{2}{|c|}{2010} & \multicolumn{2}{|c|}{2011} & \multicolumn{2}{|c|}{2012} & \multicolumn{2}{|c|}{2013} \\
\hline & Não Esforço & Esforço & Não Esforço & Esforço & Não Esforço & Esforço & Não Esforço & Esforço & Não Esforço & Esforço \\
\hline 5 vezes & $64.1 \%$ & $35.9 \%$ & $63.1 \%$ & $36.9 \%$ & $42.0 \%$ & $58.0 \%$ & $46.8 \%$ & $53.2 \%$ & $65.0 \%$ & $35.0 \%$ \\
\hline 4 vezes & $76.2 \%$ & $23.8 \%$ & $74.8 \%$ & $25.2 \%$ & $64.8 \%$ & $35.2 \%$ & $69.6 \%$ & $30.4 \%$ & $77.9 \%$ & $22.1 \%$ \\
\hline 3 vezes & $79.0 \%$ & $21.0 \%$ & $77.0 \%$ & $23.0 \%$ & $62.9 \%$ & $37.1 \%$ & $72.4 \%$ & $27.6 \%$ & $81.2 \%$ & $18.8 \%$ \\
\hline 2 vezes & $83.5 \%$ & $16.5 \%$ & $80.6 \%$ & $19.4 \%$ & $70.7 \%$ & $29.3 \%$ & $73.1 \%$ & $26.9 \%$ & $84.7 \%$ & $15.3 \%$ \\
\hline $1 \mathrm{vez}$ & $75.2 \%$ & $24.8 \%$ & $72.6 \%$ & $27.4 \%$ & $69.4 \%$ & $30.6 \%$ & $72.1 \%$ & $27.9 \%$ & $76.6 \%$ & $23.4 \%$ \\
\hline Nenhuma & $94.2 \%$ & $5.8 \%$ & $93.8 \%$ & $6.2 \%$ & $93.1 \%$ & $6.9 \%$ & $96.9 \%$ & $3.1 \%$ & $92.8 \%$ & $7.2 \%$ \\
\hline
\end{tabular}

Por fim, os resultados de percepção de esforço corroboram os resultados obtidos com a estimação original realizada através da equação (9). Portanto, os resultados da 
análise de robustez utilizando um grupo de variáveis do vetor de características X indica um efeito menor o impacto da política de bônus na realização de esforço por melhores notas por parte das escolas, mas, em ambos os casos, chega-se a mesma conclusão: a política de bônus tem pouco impacto no desempenho adicional observado nas escolas após a implementação da política. O ambiente no qual essas escolas estão inseridas possui papel mais relevante na definição do recebimento ou não do incentivo financeiro.

\section{Considerações Finais}

Foram realizados os cálculos das proporções das escolas que receberiam o bônus dadas as características e estruturas escolares nos mesmos anos em dois ambientes: aquele no qual as escolas estão expostas à política de bonificação e aquele no qual não estão. A partir dessa estimação pode-se concluir se a política gera esforços para a mudança da qualidade do ensino das escolas ou se ajuda a perpetuar as diferenças de desempenho entre escolas inseridas em distintas realidades socioeconômicas.

Com a criação do ambiente contrafactual foi possível analisar o desempenho das escolas paulistas sem o impacto do incentivo que a política gera por melhores resultados. Esse ambiente também tornou possível a análise da situação de cada escola, permitindo verificar se essas escolas já possuiam um alto ou baixo desempenho e se a política alterou os possíveis resultados que seriam observados.

O que se pôde perceber foi que a política gera baixo incentivo para que as escolas melhorem seus resultados e atinjam as metas pré-estabelecidas através da melhora da qualidade do ensino. Escolas com alto desempenho no ambiente contrafactual acabam recebendo o bônus em quase todos os anos observados, com um incremento de nota suficiente para atingir as metas a cada ano. Com isso percebe-se que a manutenção de alguma política de incentivo a melhores performances no exame padronizado acaba se dando apenas pela manutenção, por parte de funcioários da escola, dos aumentos salarias gerados pela política; e não com o fim de melhorar a qualidade do ensino, que era o principal objetivo da política de bonificação. 
Para as escolas com desempenho baixo, muitas não conseguem atingir as metas a cada ano, sendo cada vez mais difícil que se mantenham engajadas a fim de melhorarem seus métodos para oferecer uma educação de melhor qualidade.

As escolas com desempenho intermediário acabam migrando entre os dois grupos citados acima, sendo a distância entre o desempenho efetivo no ano $\mathrm{X}$ e a meta no ano $X+1$ o principal fator estimulante por melhores resultados.

Assim,foi possível concluir que o programa de bonificação beneficia escolas que já possuem um desempenho maior quando comparadas às outras principalmente pelos aspectos socioeconômicos nos quais essas escolas já estão inseridas. Escolas com baixíssimo desempenho e com alunos e professores com menores rendas familiares, além de menor exposição à educação de maneira geral (mães com menor índice de escolarização e crianças que não frequentaram o maternal), não conseguem atingir as metas mesmo em um ambiente no qual o incentivo da política não existe.

Este estudo se insere na fronteira da literatura de sistemas de bonificação, na medida em que complementa o trabalho de Bresolin (2014), que é baseado nas práticas pedagógicas das diferentes políticas brasileiras; e também o de Ferraz e Bruns (2012) com a criação do ambiente contrafactual. A maior contribuição do presente trabalho está na criação do ambiente contrafactual que permite observar o desempenho das escolas em um ambiente sem política e o crescimento gradual de performance que essas escolas já possuem, independente do incentivo gerado pela bonificação. Com esse contrafactual foi possível inferir se o esforço efetivamente realizado pelas escolas advém do incentivo ou de características existentes nas quais as escolas estão inseridas. 


\section{Referências}

ATKInson, Adele, BURGESS, Simon, CROXSON Bronwyn, GREGG, Paul, PROPPER, Carol, SLATER, Helen, WILSON, Deborah. Evaluating the impact of performance - related pay for teachers in England. Labour Economics, n.16, p.251-261, 2009

BRESOLIN, Antonio Bara. Análise de Resultados Intermediários das Políticas de Bônus em Escolas Públicas Estaduais Brasileiras. 2014. 66 f. Dissertação (Mestrado) Curso de Administração Pública e Governo, Fundação Getúlio Vargas, São Paulo, 2014

DEE, Thomas S., WYCKOFF, James. Incentives, selection and teacher performance: evidence from IMPACT. Journal of Policy Analysis an Management, vol.34, n.2, p.267-297, 2015

DUFLO, Esther, HANNA, Rema, RYAN, Stephen P.. Incentives Work: Getting Teachers to Come to School. Economic Review, v.102, n.4, p.1241-1278, 2012

FERRAZ, Claudio, BRUNS, Barbara. Paying Teachers to Perform: The impact of bonus pay in Pernambuco, Brazil. World Bank, 2012

GLEWWE, Paul, ILIAS Nauman, KREMER, Michael. Teacher Incentives. National Bureau of Economic Research, Working Paper No 9671, abr. 2003

HANUSHEK, Eric A., KAIN, John F., RIVKIN, Steven G.. Do higher salaries buy better teachers? National Bureau of Economic Research, Working Paper No 7082, abr. 1999

HANUSHEK, Eric A., KAIN, John F., RIVKIN, Steven G.. Teachers, schools and academic achievement. Econometrica, vol.73, n.2, p.417-458, 2005

LAVY, Victor. Performance Pay and Teachers' Effort, Productivity and Grading Ethics. National Bureau of Economic Research, Working Paper No 10622, jun. 2004

LAZEAR, Edward P. Paying teachers for performance: Incentives and Selection. Stanford University, ago. 2001

MURALIDHARAN, Karthik, SUNDARARAMAN,Venkatesh. Teacher Performance Pay: Experimental Evidence from India. National Bureau of Economic Research, Working Paper No 15323, set. 2009

OSHIRO, Cláudia H., SCORZAFAVE, Luiz G.. Efeito do pagamento de bônus aos professores sobre a proficiência no Estado de São Paulo. In: Encontro Nacional de Economia, 39, 2011, Foz do Iguaçu. Anais do $39^{\circ}$ Encontro Nacional de Economia. Foz do Iguaçu: Anpec, 2011

SCORZAFAVE, Luiz G., FERREIRA, Juliana N., DORIGAN, Tulio A.. Efeito das políticas de bonificação aos professores sobre a desigualdade de proficiência no ensino fundamental. In: Seminários Acadêmicos, 2014, São Paulo. Fundação Getúlio Vargas 
TAVARES, Priscilla, PONCZEK, Vladimir. Efeitos de aumentos salariais e do pagamento potencial de bônus a professores sobre a proficiência dos estudantes. Fundação Getúlio Vargas, São Paulo, 2014

VELOSO,F. Experiências de Reforma Educacional nas Últimas Duas Décadas: o que Podemos Aprender?. In: VELOSO,F. (Org), Educação Básica no Brasil. Rio de Janeiro: Elsevier, 2009. 

Anexos 



\section{ANEXO A - Parâmetros utilizados para a criação do contrafactual}

Tabela 15: Parâmetros observados na estimação da equação (9) - 50 ano

\begin{tabular}{lccccccccccc}
\hline \multirow{2}{*}{ Variáveis } & \multicolumn{3}{c}{2009} & \multicolumn{2}{c}{2010} & \multicolumn{2}{c}{2011} & \multicolumn{2}{c}{2012} & \multicolumn{2}{c}{2013} \\
\cline { 2 - 11 } & Média & DP & Média & DP & Média & DP & Média & DP & Média & DP \\
\hline Nota 2007 & 0.33 & 0.00 & 0.27 & 0.00 & 0.13 & 0.00 & 0.13 & 0.00 & 0.08 & 0.02 \\
Escola possui biblioteca & 0.04 & 0.16 & 0.02 & 0.00 & 0.01 & 0.06 & 0.03 & 0.05 & 0.01 & 0.08 \\
Professor possui pós graduação & 0.07 & 0.00 & 0.02 & 0.00 & 0.01 & 0.70 & 0.04 & 0.36 & 0.08 & 0.24 \\
Salário do Professor menor que $\mathrm{R} \$ 1.500,00$ & -0.19 & 0.00 & 0.00 & 0.84 & -0.03 & 0.34 & -0.02 & 0.31 & -0.02 & 0.45 \\
Diretor possui pós graduação & 0.14 & 0.06 & 0.12 & 0.07 & 0.19 & 0.11 & 0.06 & 0.04 & 0.08 & 0.11 \\
Salário do Diretor menor que $\mathrm{R} \$ 1.500,00$ & -0.03 & 0.05 & -0.12 & 0.20 & -0.06 & 0.16 & -0.02 & 0.04 & -0.01 & 0.07 \\
Aluno mora com a mãe & 0.11 & 0.05 & 0.35 & 0.00 & 0.63 & 0.00 & 0.43 & 0.01 & 0.15 & 0.05 \\
Mãe tem pelo menos o Ensino Médio Completo & 2.23 & 0.00 & 1.02 & 0.00 & 1.55 & 0.00 & 1.77 & 0.08 & 1.89 & 0.00 \\
Renda familiar maior que um salário mínimo & 0.71 & 0.00 & 1.72 & 0.00 & 0.37 & 0.00 & 0.26 & 0.13 & 1.44 & 0.24 \\
Aluno fez o maternal & 0.96 & 0.00 & 1.31 & 0.03 & 1.04 & 0.10 & 1.03 & 0.06 & 1.09 & 0.04 \\
\hline
\end{tabular}

Tabela 16: Parâmetros observados na estimação da equação (9) - $9^{\circ}$ ano

\begin{tabular}{lcccccccccc}
\hline \multirow{2}{*}{ Variáveis } & \multicolumn{3}{c}{2009} & \multicolumn{2}{c}{2010} & \multicolumn{2}{c}{2011} & \multicolumn{2}{c}{2012} & \multicolumn{2}{c}{2013} \\
\cline { 2 - 12 } & Média & DP & Média & DP & Média & DP & Média & DP & Média & DP \\
\hline Nota 2007 & 0.40 & 0.00 & 0.55 & 0.10 & 0.08 & 0.09 & 0.20 & 0.09 & 0.13 & 0.00 \\
Escola possui biblioteca & 0.02 & 0.00 & 0.03 & 0.03 & 0.04 & 0.04 & 0.01 & 0.05 & 0.05 & 0.08 \\
Professor possui pós graduação & 0.07 & 0.00 & 0.08 & 0.35 & 0.05 & 0.00 & 0.08 & 0.17 & 0.04 & 0.00 \\
Salário do Professor menor que $\mathrm{R} \$ 1.500,00$ & -0.04 & 0.00 & -0.03 & 0.62 & -0.06 & 0.00 & -0.01 & 0.00 & -0.04 & 0.00 \\
Diretor possui pós graduação & 0.10 & 0.00 & 0.03 & 0.06 & 0.04 & 0.29 & 0.02 & 0.04 & 0.03 & 0.04 \\
Salário do Diretor menor que R $\$ 1.500,00$ & -0.06 & 0.00 & -0.05 & 0.06 & -0.02 & 0.13 & -0.06 & 0.02 & 0.00 & 0.00 \\
Aluno mora com a mãe & 0.24 & 0.21 & 0.09 & 0.07 & 0.23 & 0.00 & 0.09 & 0.07 & 0.48 & 0.17 \\
Mãe tem pelo menos o Ensino Médio Completo & 2.32 & 0.00 & 1.12 & 0.04 & 1.54 & 0.00 & 1.52 & 0.00 & 1.37 & 0.01 \\
Renda familiar maior que um salário mínimo & 0.82 & 0.00 & 0.94 & 0.00 & 0.11 & 0.08 & 0.34 & 0.12 & 1.55 & 0.00 \\
Aluno fez o maternal & 1.66 & 0.00 & 1.39 & 0.01 & 1.75 & 0.00 & 1.13 & 0.16 & 1.62 & 0.00 \\
\hline
\end{tabular}

